Check for updates

Cite this: Mater. Adv., 2022, 3, 1101

Received 11th October 2021

Accepted 9th November 2021

DOI: 10.1039/d1ma00943e

rsc.li/materials-advances

\section{Facet control of manganese oxides with diverse redox abilities and acidities for catalytically removing hazardous 1,2-dichloroethane $\dagger$}

\author{
Baicheng Shi, Zhaoying Di, Xiaonan Guo, Ying Wei, (D) Runduo Zhang (D) * and \\ Jingbo Jia*
}

\begin{abstract}
The preparation of four kinds of $\mathrm{MnO}_{2}$, namely, $\alpha-, \beta-, \gamma-$, and $\delta$-type $\mathrm{MnO}_{2}$, with distinct crystal phases and tunnel structures was achieved and they were applied for catalytic combustion of 1,2dichloroethane (1,2-DCE). The redox ability and acidity of $\mathrm{MnO}_{2}$ as well as the corresponding reaction mechanism were studied by means of various surface-sensitive techniques, including TPR, TPD, OIE, XPS, and in situ DRIFTS together with DFT calculations. The catalytic activities for 1,2-DCE combustion demonstrated that $\gamma-\mathrm{MnO}_{2}$ displayed the most superior activity with the maximum $\mathrm{HCl}$ yield of $95 \%$ and $\mathrm{CO}_{2}$ yield of $92 \%$ due to its abundant oxygen vacancies on the surface, easy formation of reactive oxygen species, and strong acidity to readily react with the adsorbed reactant to form $\mathrm{HCl}$, which reflects the synergistic effect of its redox properties and acidity. However, the strong $\mathrm{Mn}-\mathrm{Cl}$ bonding associated with high valence $\mathrm{Mn}^{4+}$ and the scarcity of acidic sites in $\beta$ - and $\delta-\mathrm{MnO}_{2}$ hinder the $\mathrm{HCl}$ elimination process, even leading to the undesirable chlorine deposition associated with a series of polychlorinated byproducts including $1,1,2-\mathrm{C}_{2} \mathrm{H}_{3} \mathrm{Cl}_{3}$ and $\mathrm{CCl}_{4}$ via a $\mathrm{Cl}$ substitution process. A mechanism for 1,2-DCE combustion involving dehydrochlorination via $\mathrm{C}-\mathrm{Cl}$ bond cleavage at acidic sites as well as excess polychlorination by $\mathrm{Cl}_{2}$ over a relatively oxidative sample was accordingly proposed.
\end{abstract}

\section{Introduction}

In recent years, the situation of outdoor air pollution has become more and more serious. As major air pollutants, volatile organic compounds (VOCs) have attracted plenty of attention because of their contribution to the increase of ground-level ozone concentration and the formation of photochemical smog. ${ }^{1,2}$ Moreover, chlorinated volatile organic compounds (CVOCs) have high toxicity, volatility, low biodegradability and stability, ${ }^{3}$ and exhibit deleterious effect on the environmental ecosystem and human health. ${ }^{4}$ In order to eliminate CVOCs, many control technologies such as ab/ adsorption, condensation, biodegradation, non-thermal plasma, biological degradation, and catalytic combustion have been adopted. ${ }^{5-7}$ Among them, catalytic combustion is the most promising strategy owing to its high purification efficiency and product selectivity, energy-saving nature and less

State Key Laboratory of Chemical Resource Engineering, Beijing Key Laboratory of Energy Environmental Catalysis, Beijing University of Chemical Technology,

Beijing 100029, P. R. China.E-mail: zhangrd@mail.buct.edu.cn,

jiajb@mail.buct.edu.cn

$\dagger$ Electronic supplementary information (ESI) available. See DOI: 10.1039/ d1ma00943e secondary pollution. The challenge is the development of desirable catalysts for practical applications. ${ }^{8,9}$

Noble-metal catalysts ${ }^{10}$ zeolite catalysts, ${ }^{11,12}$ and transitionmetal-oxide catalysts ${ }^{8,13}$ have previously been applied for the catalytic combustion of CVOCs. Noble-metal catalysts commonly show high activity at low temperatures, but their large-scale application is limited by their high cost and sensitivity to chlorine poisoning. ${ }^{14}$ The abundant acid sites of zeolite catalysts can promote the dechlorination of CVOCs, but it can easily cause carbon deposition. ${ }^{15}$ Transition-metal-oxide catalysts are also employed for catalytic combustion of CVOCs due to their considerable activity, easily-controllable nanostructure and attractive resistance towards chlorine poisoning. ${ }^{16,17} \mathrm{~A}$ yolkshell-like mesoporous $\mathrm{CoCrO}_{x}$ was prepared for deep destruction of dichloromethane and it was found that the strong interaction of $\mathrm{Co}$ and $\mathrm{Cr}$ elements can generate active $\mathrm{Cr}^{6+}$ and oxygen species, which enhanced the catalytic activity. ${ }^{18}$ Although the Cr component shows good catalytic activity for purifying CVOCs, its application could cause potential harm to animals and humans. ${ }^{19}$ Among many transition-metal catalysts, $\mathrm{MnO}_{x}$ possess excellent redox properties and adjustable valence states, and have attracted much attention in CVOC combustion. ${ }^{20}$ Two $\alpha$ $\mathrm{Mn}_{2} \mathrm{O}_{3}$ single crystals exposed with the $\left(\begin{array}{lll}1 & 1 & 1\end{array}\right)$ facet and exposed

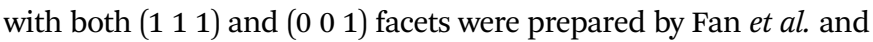


applied for the selective catalytic reduction (SCR) of $\mathrm{NO}_{x}$ with $\mathrm{NH}_{3}$, and it was found that the charge redistribution on the surface of the $\left(\begin{array}{lll}0 & 0 & 1\end{array}\right)$ facet, which produced more adsorption sites, benefited further adsorption and reaction of $\mathrm{NH}_{3}$ and $\mathrm{NO}$ molecules and improved the catalytic activity. ${ }^{21}$ Wang et al. prepared a series of $\mathrm{MnO}_{x}$ including $\gamma-\mathrm{MnO}_{2}, \mathrm{Mn}_{2} \mathrm{O}_{3}$ and $\mathrm{Mn}_{3} \mathrm{O}_{4}$, which were used for catalytic oxidation of benzene and 1,2-DCE, and noted that $\gamma-\mathrm{MnO}_{2}$ exhibited remarkable activity ascribed to the abundant surface absorbed oxygen species and ideal low-temperature reducibility. ${ }^{22}$ According to the different tunnel structures of $\mathrm{MnO}_{2}$ formed by $\mathrm{MnO}_{6}$ octahedra connected by common vertices or edges linked into a single chain or double chain structure, ${ }^{23}$ the crystal phase of $\mathrm{MnO}_{2}$ can be divided into a one-dimensional ( $\alpha$-, $\beta$ - and $\gamma$-type) tunnel structure and a twodimensional ( $\delta$-type) layer structure. Li et al. improved the $\mathrm{MnO}_{2}$ activity via in situ fabrication of a three-dimensional (3D) macroporous $\gamma-\mathrm{MnO}_{2} / \mathrm{LaMnO}_{3.15}$ and revealed that the outstanding activity may be ascribed to the increased BET surface area and the enhanced active reactive oxygen species quantity after $\gamma-\mathrm{MnO}_{2} / \mathrm{LaMnO}_{3.15}$ modification. ${ }^{24}$ Zhang et al. elaborated the mechanism of catalytic combustion of 1,2-dichloropropane over the $\mathrm{LaMnO}_{3}$ perovskite through experimental and theoretical studies, indicating that further decomposition was strongly dependent on the active reactive oxygen species and the rate-determining step for catalytic oxidation of 1,2-dichloropropane was decided by the reaction conditions. ${ }^{25}$ Wang et al. introduced $\mathrm{CeO}_{2}$ and $\mathrm{HF}$ etching to modify $\mathrm{LaMnO}_{3}$ and found that it could resist the catalyst deactivation, which showed that the loaded $\mathrm{CeO}_{2}$ provided enriched oxygen vacancies to retain the redox ability and the fluoride ions replaced the surface lattice oxygens to promote the mobility of oxygen species. ${ }^{26}$ Weng et al. explored the influence of phosphoric acid etching and water vapor on dichloromethane elimination over $\mathrm{La}_{3} \mathrm{Mn}_{2} \mathrm{O}_{7}$ and found that the former enhanced dichloromethane hydrolysis and the latter promoted desorption of accumulative chlorine with elevated temperatures. ${ }^{27}$ However, the study on CVOC combustion over $\mathrm{MnO}_{2}$ with different crystal planes has rarely been reported. What is more, how to improve the anti-poisoning ability of catalysts and avoid deactivation and production of more harmful by-products is still a challenge in industrial applications.

As a kind of typical CVOCs, 1,2-dichloroethane (1,2-DCE) is often used as a solvent, extractant and raw material for organic synthesis and its catalytic combustion over $\mathrm{MnO}_{2}$ with diverse crystal structures has not been explored. The preparation of $\alpha$-, $\beta$-, $\gamma$-, and $\delta$-type $\mathrm{MnO}_{2}$ with different crystal phases and tunnel structures was achieved and used for catalytic combustion of 1,2-DCE in this work. What is more, a lot of characterization studies were carried out to reveal the relationship between their physicochemical properties and catalytic activity and the reaction mechanism was also studied.

\section{Experimental}

\subsection{Preparation of $\mathrm{MnO}_{2}$ catalysts}

Four kinds of $\mathrm{MnO}_{2}$ catalysts with distinct crystal phases and tunnel structures were successfully prepared. All reagents used in this work were analytically pure and used without any treatment. The typical synthesis methods are described in the ESI. $\dagger$

\subsection{Catalyst characterization}

The crystallographic information was investigated by XRD using a diffractometer equipped with $\mathrm{Cu} \mathrm{K}_{\alpha}$ radiation (Bruker, Germany). The specific surface areas $\left(S_{\mathrm{BET}}\right)$ were determined using $\mathrm{N}_{2}$ sorption isothermal analysis (Quantachrome, USA) based on Brunauer-Emmett-Teller (BET) theory. TPR and TPD experiments were carried out on a device with a thermal conductivity detector (TCD, Huasi, China). SEM (S-4800, Hitachi, Japan) was used to observe the morphologies of the prepared $\mathrm{MnO}_{2}$ solids under a $5.0 \mathrm{kV}$ accelerating voltage, and HRTEM (JEM-2100, JEOL, Japan) was employed to observe the microstructures under a $200 \mathrm{kV}$ operating voltage. XPS instrument (Shimadzu, Japan) equipped with a monochromatic $\mathrm{Mg} / \mathrm{Al} \mathrm{K}_{\alpha}$ $\mathrm{X}$-ray source was used to analyze the superficial elemental properties. The in situ DRIFTS experiments were conducted with a spectrometer (Bruker, Germany) equipped with a mercury cadmium telluride (MCT) detector. The details are given in the ESI. $\dagger$

\subsection{Temperature programmed oxygen isotopic exchange (TPOIE) reaction}

TPOIE has been used to evaluate oxygen mobility in a wide temperature range. ${ }^{28-30}$ In this study, the simple heterogeneous oxygen isotopic exchange (OIE) mechanism was involved over the as-prepared samples, and the experimental device, operation method and schematic diagram are depicted in the ESI. $\dagger$

\subsection{Density functional theory (DFT) calculations}

During the theoretical simulation, the slab models were reconstructed using a $[2 \times 2 \times 1]$ supercell, and the slabs were periodically repeated with a vacuum spacing of $15 \AA$ for oxygen vacancy formation. All slab calculations were performed using a Monkhorst-Pack grid ( $3 \times 3 \times 1$ mesh) with a cutoff energy of $400 \mathrm{eV}$ and the smearing parameter set to $0.1 \mathrm{eV}$. The constraint value was set to $5 \times 10^{-6}$ energy charge between two consecutive iterations to achieve SCF convergence. The computational details are given in the ESI. $\dagger$

\subsection{Catalytic activity evaluation}

The catalytic performance was investigated on a catalyst bed with a quartz tube (i.d. $=4 \mathrm{~mm}) .0 .14 \mathrm{~g}$ of catalyst $(40-60 \mathrm{mesh})$

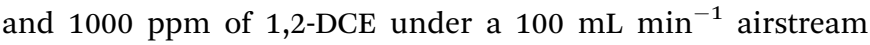
(20 vol\% $\mathrm{O}_{2} ; \mathrm{N}_{2}$ balanced) with a gas hourly space velocity (GHSV) of $42857 \mathrm{~mL} \mathrm{~g}^{-1} \mathrm{~h}^{-1}$ were used in each test. The reaction was performed from 100 to $500{ }^{\circ} \mathrm{C}$ in a step mode with a 30 min plateau at each temperature. The outlet gases were measured with an online gas chromatograph (Agilent 7890B) equipped with a TCD and a mass spectrometer (Agilent 5977A). 


\section{Results and discussion}

\subsection{Structural and morphological characterization}

As illustrated in Fig. 1, it is clearly observed that $\mathrm{MnO}_{2}$ catalysts are well indexed to the crystal phases corresponding to JCPDS Card Numbers 44-0141 ( $\alpha-)$, 24-0735 ( $\beta-), 14-0644(\gamma-)$ and 80-1098 $(\delta-)$, respectively. This confirms that the expected $\mathrm{MnO}_{2}$ phases were successfully obtained. $\beta-\mathrm{MnO}_{2}$ had better crystallinity originating from the narrow peak width and high intensity. As reported, $\beta-\mathrm{MnO}_{2}$ is favorable for grain growth due to its regular arrangement of $\left[\mathrm{MnO}_{6}\right]$ octahedra. ${ }^{23}$ The peaks of $\gamma-\mathrm{MnO}_{2}$ were relatively wide, suggesting it possessed lower crystallinity. $\gamma-\mathrm{MnO}_{2}$ has been reported to be ordinarily composed of hybrid phases in which pyrolusite and ramsdellite intergrow irregularly. ${ }^{31}$

The type and size of tunnels, BET surface areas $\left(S_{\mathrm{BET}}\right)$, and pore volumes of the four catalysts are shown in Table 1 and Fig. 2. It is reported that the different tunnel structures assembled by $\mathrm{MnO}_{6}$ octahedra in $\mathrm{MnO}_{2}$ will affect the related surface areas and pore volumes. ${ }^{32} \alpha$ - and $\beta-\mathrm{MnO}_{2}$ presented relatively low specific surface areas (35.9 and $29.9 \mathrm{~m}^{2} \mathrm{~g}^{-1}$, respectively) and pore volumes $\left(0.207\right.$ and $0.191 \mathrm{~cm}^{3} \mathrm{~g}^{-1}$, respectively), while $\gamma$ - and $\delta-\mathrm{MnO}_{2}$ showed higher specific surface areas (87.4 and $86.5 \mathrm{~m}^{2} \mathrm{~g}^{-1}$, respectively) and pore volumes (0.313 and $0.271 \mathrm{~cm}^{3} \mathrm{~g}^{-1}$, respectively). Among them, $\gamma-\mathrm{MnO}_{2}$ has the largest specific surface area and pore volume. What is more, the nitrogen adsorption-desorption isotherms of $\gamma$ - and $\delta-\mathrm{MnO}_{2}$ display a type $\mathrm{V}$ curve with $\mathrm{H} 3$ type hysteresis loops, which implies the existence of mesoporous structures in these two samples. However, the wide relative pressure range of hysteresis loops of $\delta-\mathrm{MnO}_{2}$ suggests that pseudopores are formed by the secondary construction of lamellar particles.

The SEM and TEM images of the as-prepared samples are presented in Fig. 3. $\alpha-\mathrm{MnO}_{2}$ presents a linear nanoneedle morphology with a length of 2-2.5 $\mu \mathrm{m}$ and width of 25$30 \mathrm{~nm}$, which are interspersed and staggered with each other. The well-identified periodic lattice fringes of $6.90 \AA$ size in

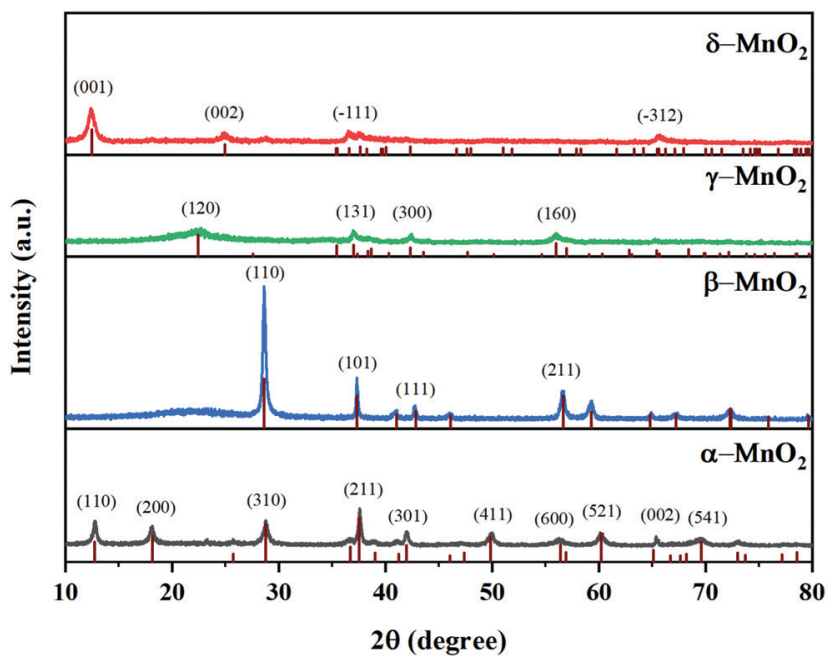

Fig. 1 The XRD patterns of $\mathrm{MnO}_{2}$.
Table 1 Tunnel structures and sizes, BET surface areas, and pore volumes of the samples

\begin{tabular}{|c|c|c|c|c|}
\hline Samples & Tunnel $^{33}$ & Size $(\AA)^{33}$ & $S_{\mathrm{BET}}\left(\mathrm{m}^{2} \mathrm{~g}^{-1}\right)$ & $\begin{array}{l}\text { Pore volume (V) } \\
\left(\mathrm{cm}^{3} \mathrm{~g}^{-1}\right)\end{array}$ \\
\hline$\alpha-\mathrm{MnO}_{2}$ & $(1 \times 1),(2 \times 2)$ & $1.89,4.6$ & 35.9 & 0.207 \\
\hline$\beta-\mathrm{MnO}_{2}$ & $(1 \times 1)$ & 1.89 & 29.9 & 0.191 \\
\hline$\gamma-\mathrm{MnO}_{2}$ & $(1 \times 1),(1 \times 2)$ & $1.89,2.3$ & 87.4 & 0.313 \\
\hline$\delta-\mathrm{MnO}_{2}$ & Interlayer distance & 7.0 & 86.5 & 0.271 \\
\hline
\end{tabular}

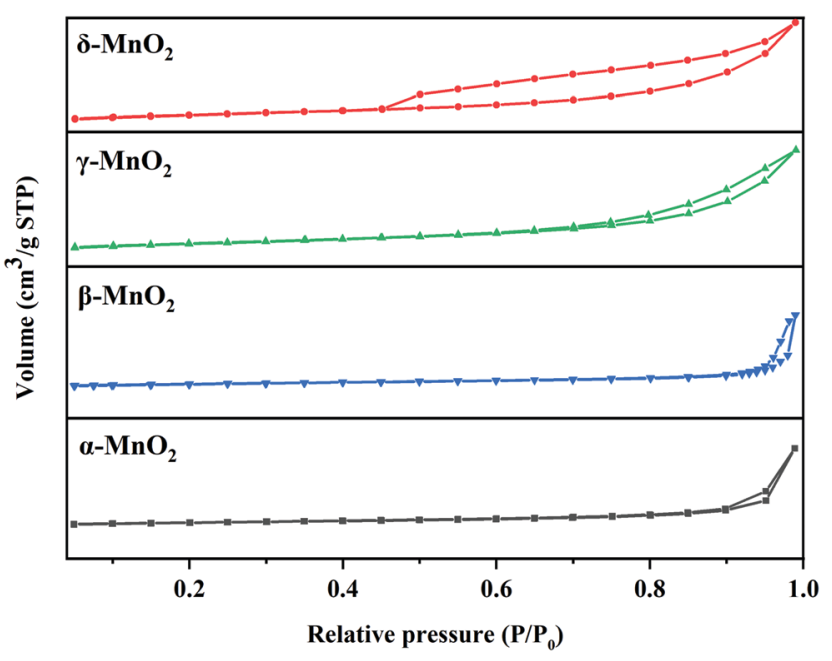

Fig. 2 The nitrogen adsorption-desorption isotherms of $\mathrm{MnO}_{2}$.

Fig. 3(a4) correspond to the (1 110 ) facet of $\alpha-\mathrm{MnO}_{2} \cdot \beta-\mathrm{MnO}_{2}$ shows a nanorod-shaped structure with a similar length to that of $\alpha-\mathrm{MnO}_{2}$ and a width $2-5$ times that of $\alpha-\mathrm{MnO}_{2}$. The wellidentified periodic lattice fringes of $2.39 \AA$ size correspond to the $\left(\begin{array}{lll}1 & 0 & 1\end{array}\right)$ facet of $\beta-\mathrm{MnO}_{2}$ in Fig. 3(b4). $\gamma-\mathrm{MnO}_{2}$ presents a spherical nanostructure, which is assembled by interlaced sharp nanoneedles. The nanoneedles are $\sim 30 \mathrm{~nm}$ in diameter and $\sim 1 \mu \mathrm{m}$ in length. The lattice fringes with distances of $3.98 \AA$ and $2.42 \AA$ match well the $\left(\begin{array}{lll}1 & 3 & 1\end{array}\right)$ and $\left(\begin{array}{lll}1 & 2 & 0\end{array}\right)$ facets in Fig. 3(c4), respectively. $\delta-\mathrm{MnO}_{2}$ shows a flower-globular nanostructure, which is different from the spherical structure of $\gamma-\mathrm{MnO}_{2}$. It is made up of a large number of small nanosheets intertwined with each other, and the width of these nanosheets is about $15-25 \mathrm{~nm}$. A typical interlayer spacing of $3.47 \AA$ in $\delta-\mathrm{MnO}_{2}$ can be observed in Fig. 3(d4).

\section{$3.2 \quad \mathrm{H}_{2}$-TPR and $\mathrm{O}_{2}$-TPD}

The $\mathrm{H}_{2}$-TPR profiles can be seen in Fig. 4 a with $\mathrm{H}_{2}$ consumption depicted in Table 2 . Two reduction peaks of each sample emerge from the reduction of $\mathrm{MnO}_{2}$ to $\mathrm{Mn}_{2} \mathrm{O}_{3} / \mathrm{Mn}_{3} \mathrm{O}_{4}$ and successive reduction to $\mathrm{MnO}$, respectively. ${ }^{34}$ The reduction peaks of $\alpha-\mathrm{MnO}_{2}$ are overlapped and centered at 307 and $354{ }^{\circ} \mathrm{C}$. The ratio of the $\mathrm{H}_{2}$ consumption amount between the former reduction peak and the latter peak of $\alpha-\mathrm{MnO}_{2}$ was calculated to be about $1: 1$, which reveals that the reduction of $\alpha-\mathrm{MnO}_{2}$ might proceed as follows: $\mathrm{MnO}_{2} \rightarrow \mathrm{Mn}_{2} \mathrm{O}_{3} \rightarrow \mathrm{MnO}$. The reduction peaks of $\beta-\mathrm{MnO}_{2}$ are centered at 318 and $417{ }^{\circ} \mathrm{C}$. The $\mathrm{H}_{2}$ consumption 


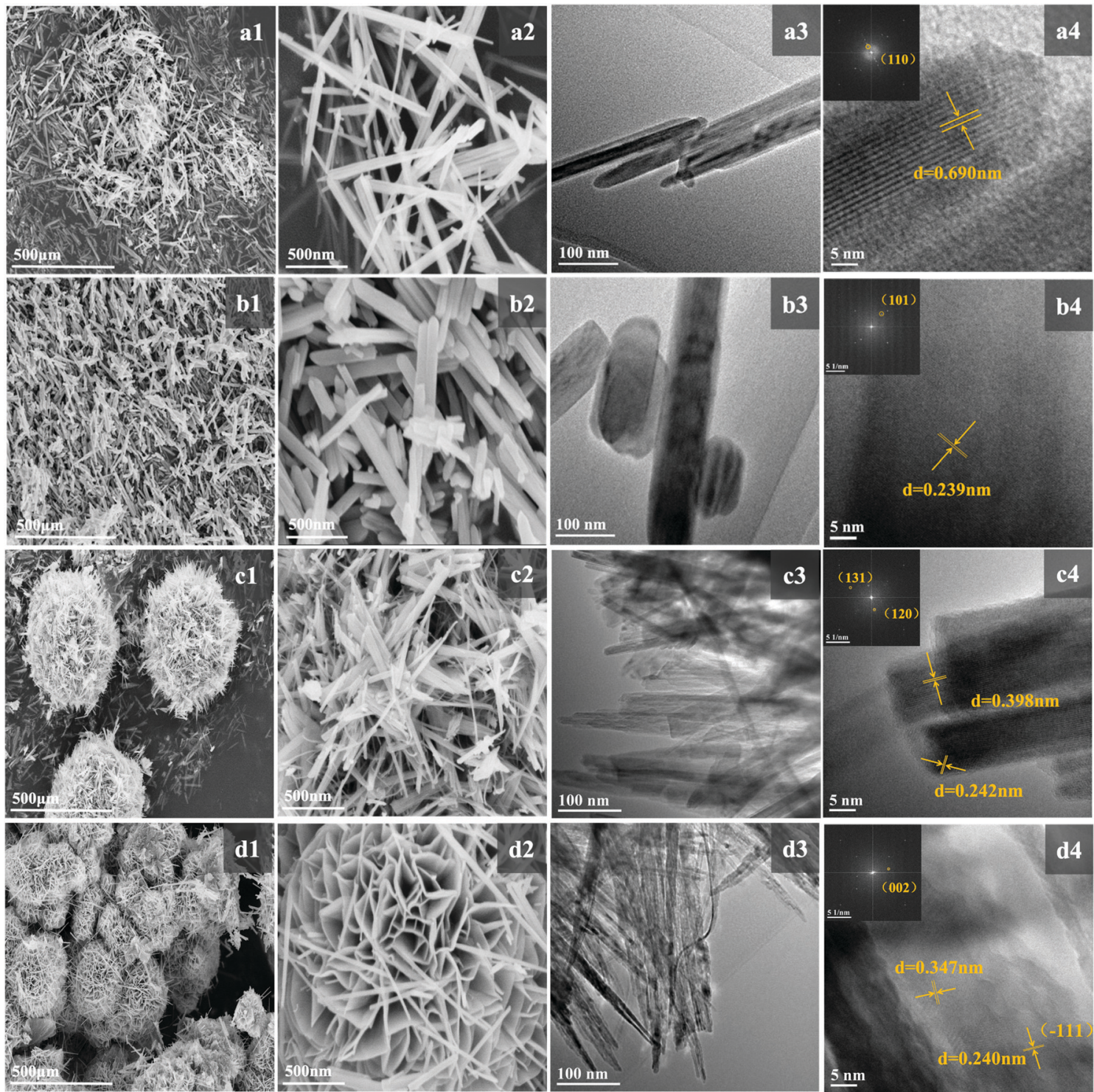

Fig. 3 The SEM and TEM images of (a) $\alpha-$, (b) $\beta-$-, (c) $\gamma$ - and (d) $\delta-\mathrm{MnO}_{2}$.

amount for the former peak is almost twice as large as that for the latter peak, suggesting that the reduction process of $\beta-\mathrm{MnO}_{2}$ follows the $\mathrm{MnO}_{2} \rightarrow \mathrm{Mn}_{3} \mathrm{O}_{4} \rightarrow \mathrm{MnO}$ order. The $\mathrm{H}_{2}$-TPR profile of $\gamma-\mathrm{MnO}_{2}$ exhibits a similar shape to the profile of $\beta-\mathrm{MnO}_{2}$, in which a $\mathrm{H}_{2}$ consumption peak is centered at $284{ }^{\circ} \mathrm{C}$ with a hump at $396{ }^{\circ} \mathrm{C}$. The ratio of $\mathrm{H}_{2}$ consumption of the low-temperature peak to the high-temperature peak of $\gamma-\mathrm{MnO}_{2}$ is about $2: 1$, which indicates that the reduction follows the $\mathrm{MnO}_{2} \rightarrow \mathrm{Mn}_{3} \mathrm{O}_{4} \rightarrow$ $\mathrm{MnO}$ order. For $\delta-\mathrm{MnO}_{2}$, two overlapped reduction peaks located at 288 and $331{ }^{\circ} \mathrm{C}$ were observed. The area proportion of the former peak to the latter peak is approximately $1: 1$, suggesting that $\delta-\mathrm{MnO}_{2}$ is initially reduced to $\mathrm{Mn}_{2} \mathrm{O}_{3}$ and then to $\mathrm{MnO}$. According to the location of the initial reduction peak of the $\mathrm{MnO}_{2}$ samples, the reducibility sequence is $\gamma-\mathrm{MnO}_{2} \approx \delta-\mathrm{MnO}_{2}$ $>\alpha-\mathrm{MnO}_{2} \approx \beta-\mathrm{MnO}_{2}$, which indicates that $\gamma$ - and $\delta-\mathrm{MnO}_{2}$ have better redox properties. What stands out is that $\mathrm{H}_{2}$-TPR could reveal the migration of oxygen in the four catalysts because
$\gamma-\mathrm{MnO}_{2}$ displays the lowest temperature reduction peak, and its lattice oxygen species are more mobile with respect to the other three $\mathrm{MnO}_{2}$ samples. This possibly results in more oxygen being absorbed and their further excitation as surface reactive species to participate in the reaction, which is also reflected in the TPOIE reaction below (section 3.4).

The $\mathrm{O}_{2}$-TPD profiles are presented in Fig. 4b. It was widely accepted that active physically adsorbed oxygen can be eliminated from the surface at a low temperature, and thus we can confirm that the oxygen desorption peaks at the tested temperatures are categorized as chemisorbed oxygen species. ${ }^{35}$ In the process of the reaction, molecular oxygen will be firstly absorbed on the surface of the catalysts and then converted into atomic oxygen or other surface reactive oxygen species, such as $\mathrm{O}^{-}, \mathrm{O}^{2-}$, etc. There are two peaks for $\alpha$ - and $\gamma-\mathrm{MnO}_{2}$, while there is only one peak for $\beta$ - and $\delta-\mathrm{MnO}_{2} \cdot \mathrm{MnO}_{2}$ surface was mainly covered by $\mathrm{Mn}^{3+}$ species. ${ }^{9}$ Considering $\gamma-\mathrm{MnO}_{2}$ has 

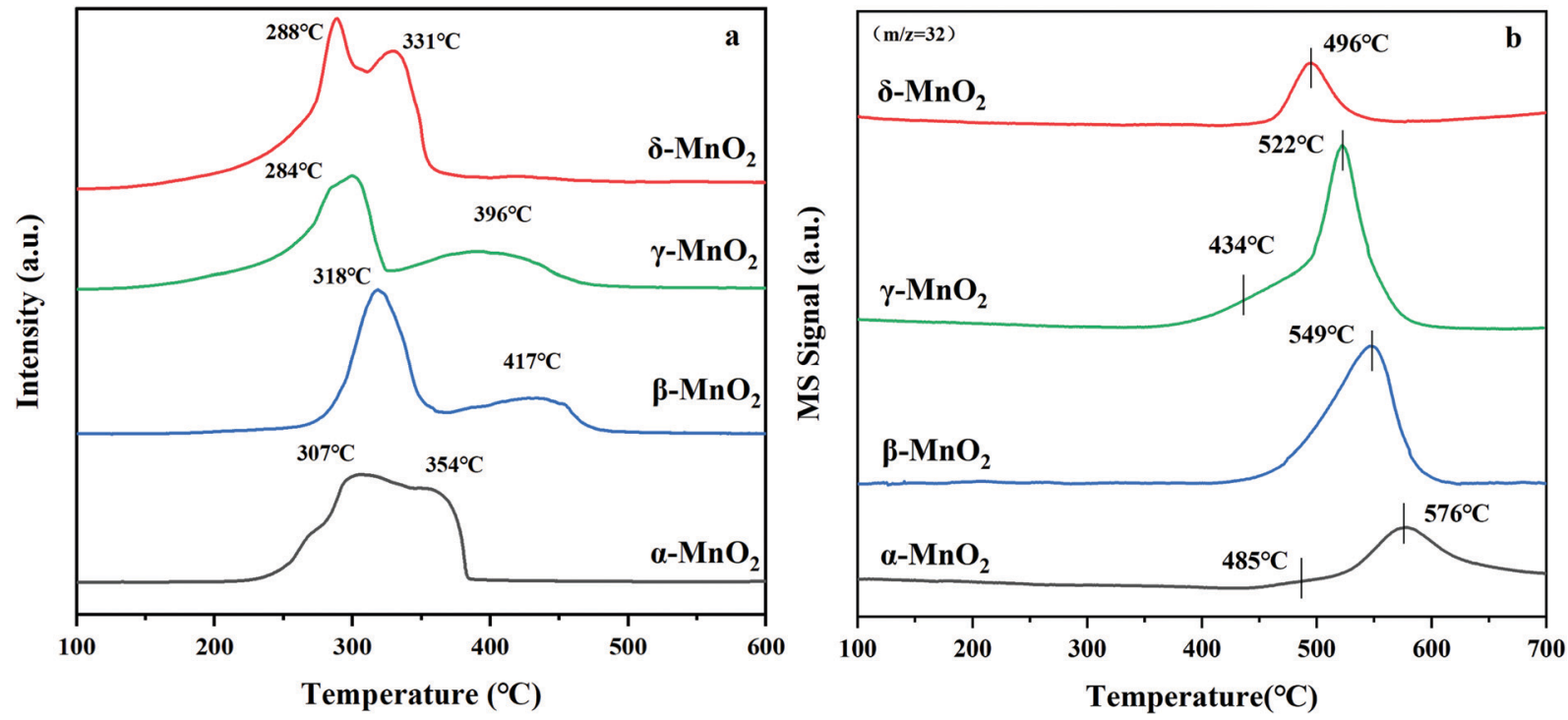

Fig. 4 The (a) $\mathrm{H}_{2}$-TPR and (b) $\mathrm{O}_{2}$-TPD profiles of $\mathrm{MnO}_{2}$.

Table 2 The total $\mathrm{H}_{2}$ consumption of $\mathrm{MnO}_{2}$

Reduction peak $\left({ }^{\circ} \mathrm{C}\right)$

Samples Position $\left({ }^{\circ} \mathrm{C}\right)$ Position $\left({ }^{\circ} \mathrm{C}\right)$ Total $\mathrm{H}_{2}$ consumption $\left(\mathrm{mmol} \mathrm{g}^{-1}\right)$

$\begin{array}{llll}\alpha-\mathrm{MnO}_{2} & 314 & 337 & 10.75\end{array}$

$\begin{array}{llll}\mathrm{BnO}_{2} & 318 & 417 & 10.82\end{array}$

$\gamma-\mathrm{MnO}_{2} 284 \quad 396 \quad 10.73$

$\delta-\mathrm{MnO}_{2} 288 \quad 331 \quad 10.94$

the lowest temperature of the first desorption peak amongst all samples, it is deduced that $\gamma-\mathrm{MnO}_{2}$ possesses superior oxygen mobility. That is to say, multitudinous surface oxygen vacancies on the surface of $\gamma-\mathrm{MnO}_{2}$ may tend to form atomic oxygen or other surface reactive oxygen species, which contributes to further oxidation of 1,2-DCE.

\subsection{XPS}

The chemical status and surface composition were acquired by XPS. Fig. 5a displays the $\mathrm{O} 1 \mathrm{~s}$ spectrum of $\mathrm{MnO}_{2}$. Generally, the $\mathrm{O}$ 1s pattern can be divided into three regions. The binding energy (BE) at 529.2-529.6 eV is ascribed to lattice oxygen $\left(\mathrm{O}_{\text {latt }}\right),{ }^{22}$ the BE at $531.6-531.8 \mathrm{eV}$ belongs to surface adsorbed oxygen $\left(\mathrm{O}_{\text {ads }}\right)$, which is naturally chemisorbed in the surrounding of the surface oxygen vacancies, ${ }^{36,37}$ and the $\mathrm{BE}$ at $533.2-533.6 \mathrm{eV}$ is ascribed to the surface hydroxyl $(\mathrm{OH})$ groups $\left(\mathrm{OH}_{\text {surf }}\right)^{22}$ Generally gaseous $\mathrm{O}_{2}$ tends to be adsorbed on the surface oxygen vacancies and these absorbed $\mathrm{O}_{2}$ could be further dissociated into atomic oxygen at a certain temperature. ${ }^{38}$ As indicated in Table 3, $\gamma-\mathrm{MnO}_{2}$ contained the most abundant surface adsorbed oxygen $\left(\mathrm{O}_{\text {ads }}\right)$ with a ratio of $\mathrm{O}_{\text {ads }}$ to total oxygen species of $49.5 \%$, which suggests that, among all the samples, $\gamma-\mathrm{MnO}_{2}$ has abundant oxygen vacancies on its surface.

Fig. $5 \mathrm{~b}$ illustrates the $\mathrm{Mn} 2 \mathrm{p}_{3 / 2}$ spectrum of $\mathrm{MnO}_{2}$. The peaks at 642.6 and $641.8 \mathrm{eV}$ can be assigned to surface $\mathrm{Mn}^{4+}$ and $\mathrm{Mn}^{3+}$ species. ${ }^{39}$ From Table 3, the quantitative calculations of the Mn $2 \mathrm{p}^{3 / 2}$ XPS were conducted and the $\mathrm{Mn}^{4+} / \mathrm{Mn}^{3+}$ molar ratio was determined. Obviously, the molar ratio of surface elements $\mathrm{Mn}^{4+} / \mathrm{Mn}^{3+}$ is distinct in these four kinds of $\mathrm{MnO}_{2}$. The $\delta-\mathrm{MnO}_{2}$ sample exhibits the maximum $\mathrm{Mn}^{4+} / \mathrm{Mn}^{3+}$ molar ratio (3.8). Besides, $\mathrm{Mn}^{4+}-\mathrm{O}$ bonds are more stable than $\mathrm{Mn}^{3+}-\mathrm{O}$ bonds. ${ }^{40}$ This suggests that $\gamma-\mathrm{MnO}_{2}$ contains more unstable $\mathrm{Mn}-\mathrm{O}$ bonds on the surface, which indicates that the atomic oxygen species absorbed on its surface are more probably released to take part in catalytic combustion. In the same way, the presence of low valence manganese on the surface could facilitate the dissociation and activation of the surrounding atomic oxygen species. ${ }^{9}$

The average oxidation state (AOS) of manganese on the surface was assessed based on Mn 3s doublet splitting $\left(\Delta E_{\mathrm{s}}\right)$ according to the following relationship: ${ }^{41}$

$$
\text { AOS }=8.956-1.126 \Delta E_{\mathrm{S}}
$$

The AOS follows the order of $\delta-\mathrm{MnO}_{2}(3.82)>\beta-\mathrm{MnO}_{2}(3.80)>$ $\alpha-\mathrm{MnO}_{2}(3.78)>\gamma-\mathrm{MnO}_{2}$ (3.76), as presented in Fig. $5 \mathrm{c}$. This rule accords well with the result of $\mathrm{H}_{2}$-TPR, which indicates that the content of $\mathrm{Mn}^{3+}$ in $\gamma-\mathrm{MnO}_{2}$ is the maximum.

\subsection{Temperature programmed oxygen isotopic exchange (TPOIE) reaction}

As mentioned above, the four samples followed the sample heterogeneous exchange mechanism, that is, exchange of one oxygen atom at a time. Here, the surface reactivity of the four samples at lower temperatures involving route (2) is accordingly investigated. The heterogeneous exchange reaction involving bulk lattice oxygens is used to evaluate their transfer ability at relatively high temperatures as formulated by route (3).

$$
{ }^{18} \mathrm{O}^{18} \mathrm{O}(g)+\mathrm{Mn}-{ }^{16} \mathrm{O}(s) \Leftrightarrow{ }^{18} \mathrm{O}^{16} \mathrm{O}(g)+\mathrm{Mn}-{ }^{18} \mathrm{O}_{\text {sur }}(\text { ads })
$$



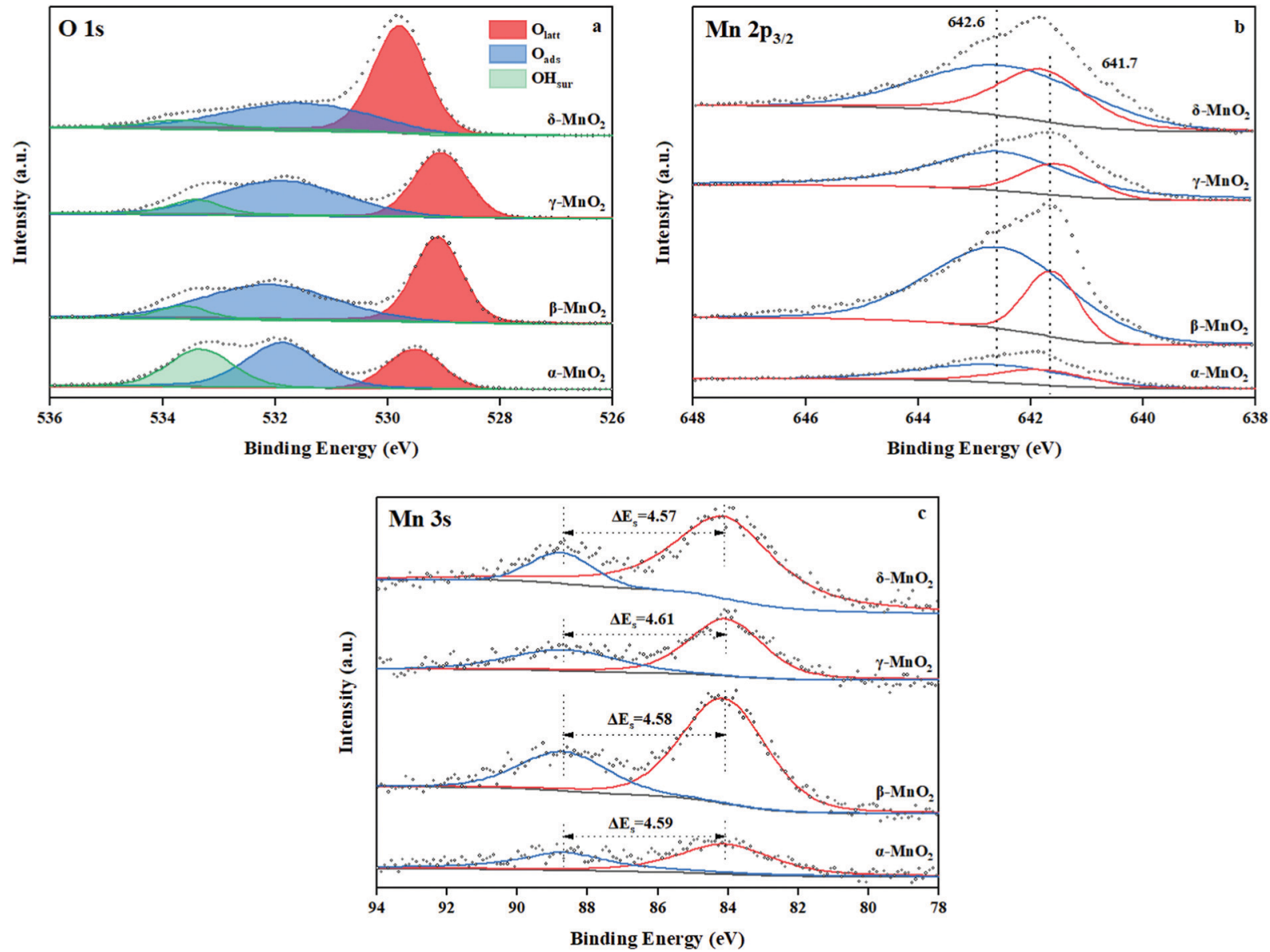

Fig. 5 The XPS of (a) O 1s, (b) $M n 2 p_{3 / 2}$, and (c) $M n$ ss of $\mathrm{MnO}_{2}$.

Table 3 The XPS results of $\mathrm{MnO}_{2}$ and the average oxidation state (AOS) calculated by $\mathrm{Mn} 3 \mathrm{~s}$ doublet splitting $\left(\Delta E_{\mathrm{s}}\right)$

\begin{tabular}{lllllll}
\hline & \multicolumn{2}{l}{ Binding energy (eV) and ratio (\%) } & & & \\
\cline { 2 - 5 } Samples & $\mathrm{O}_{\text {latt }}$ & $\mathrm{O}_{\text {ads }}$ & $\mathrm{OH}_{\text {sur }}$ & $\mathrm{Mn}^{4+}$ & $\mathrm{Mn}^{3+}$ & Average oxidation state (AOS) \\
\hline$\alpha-\mathrm{MnO}_{2}$ & $529.5 / 26.4$ & $531.7 / 43.3$ & $533.3 / 31.3$ & $642.6 / 75.9$ & $641.8 / 24.1$ & 3.78 \\
$\beta-\mathrm{MnO}_{2}$ & $529.3 / 47.0$ & $531.8 / 47.3$ & $533.5 / 5.7$ & $642.6 / 77.9$ & $641.7 / 22.1$ & 3.80 \\
$\gamma-\mathrm{MnO}_{2}$ & $529.2 / 40.6$ & $531.7 / 49.5$ & $533.4 / 9.9$ & $642.6 / 75.7$ & $641.6 / 24.3$ & 3.76 \\
$\delta-\mathrm{MnO}_{2}$ & $529.6 / 57.8$ & $531.6 / 36.4$ & $533.5 / 5.8$ & $642.5 / 79.0$ & $641.8 / 21.0$ & 3.82 \\
\end{tabular}

$$
{ }^{18} \mathrm{O}^{16} \mathrm{O}(g)+\mathrm{Mn}-{ }^{16} \mathrm{O}_{2}(s) \Leftrightarrow{ }^{16} \mathrm{O}^{16} \mathrm{O}(g)+\mathrm{Mn}-{ }^{18} \mathrm{O}^{16} \mathrm{O}(s)
$$

where $(s),(g)$ and (ads) refer to the lattice oxygen in the solid phase, gaseous oxygen in the gas phase and the adsorbed oxygen, respectively. As illustrated in Fig. 6 , the ${ }^{18} \mathrm{O}^{16} \mathrm{O}$ curve increases in the range of 200 to $400{ }^{\circ} \mathrm{C}$, but it can hardly be observed in the ${ }^{16} \mathrm{O}_{2}$ formation, which is conducive to the predominant participation of oxygen atoms, corresponding to route (2). Further increase of the temperature leads to an enhancement of the ${ }^{18} \mathrm{O}^{16} \mathrm{O}$ uptake, accompanied by ${ }^{16} \mathrm{O}_{2}$ production (400 to $600{ }^{\circ} \mathrm{C}$ ). The ${ }^{16} \mathrm{O}^{16} \mathrm{O}$ curve corresponds to route (3), which can only be observed over $\gamma-\mathrm{MnO}_{2}$. The adsorbed molecular oxygen is mainly generated by route (2), and the lattice oxygen is generated by route (3) at the same time.

From the experiment, the cumulative exchange oxygen atom amounts $\left(N_{\mathrm{e}}\right)$ and oxygen exchange rates $\left(R_{\mathrm{e}}\right)$ with temperature are obtained (Fig. 7a and b). As shown in Fig. 7a, the sum of exchanged oxygen atom amount is distinct in these four kinds of $\mathrm{MnO}_{2}$ samples. The $\gamma-\mathrm{MnO}_{2}$ sample contains the maximum amount of exchanged ${ }^{18} \mathrm{O}$ atoms and the $\alpha-\mathrm{MnO}_{2}$ sample shows the opposite result. $\gamma-\mathrm{MnO}_{2}$ has an excellent exchange ability throughout the whole temperature range $\left(200-600{ }^{\circ} \mathrm{C}\right)$ since it has bigger specific surface area for releasing and making use of the surface and lattice oxygen atoms well. What is more, a huge difference among the four $\mathrm{MnO}_{2}$ catalysts can be seen at the initial activated temperature. The temperature of exchange 

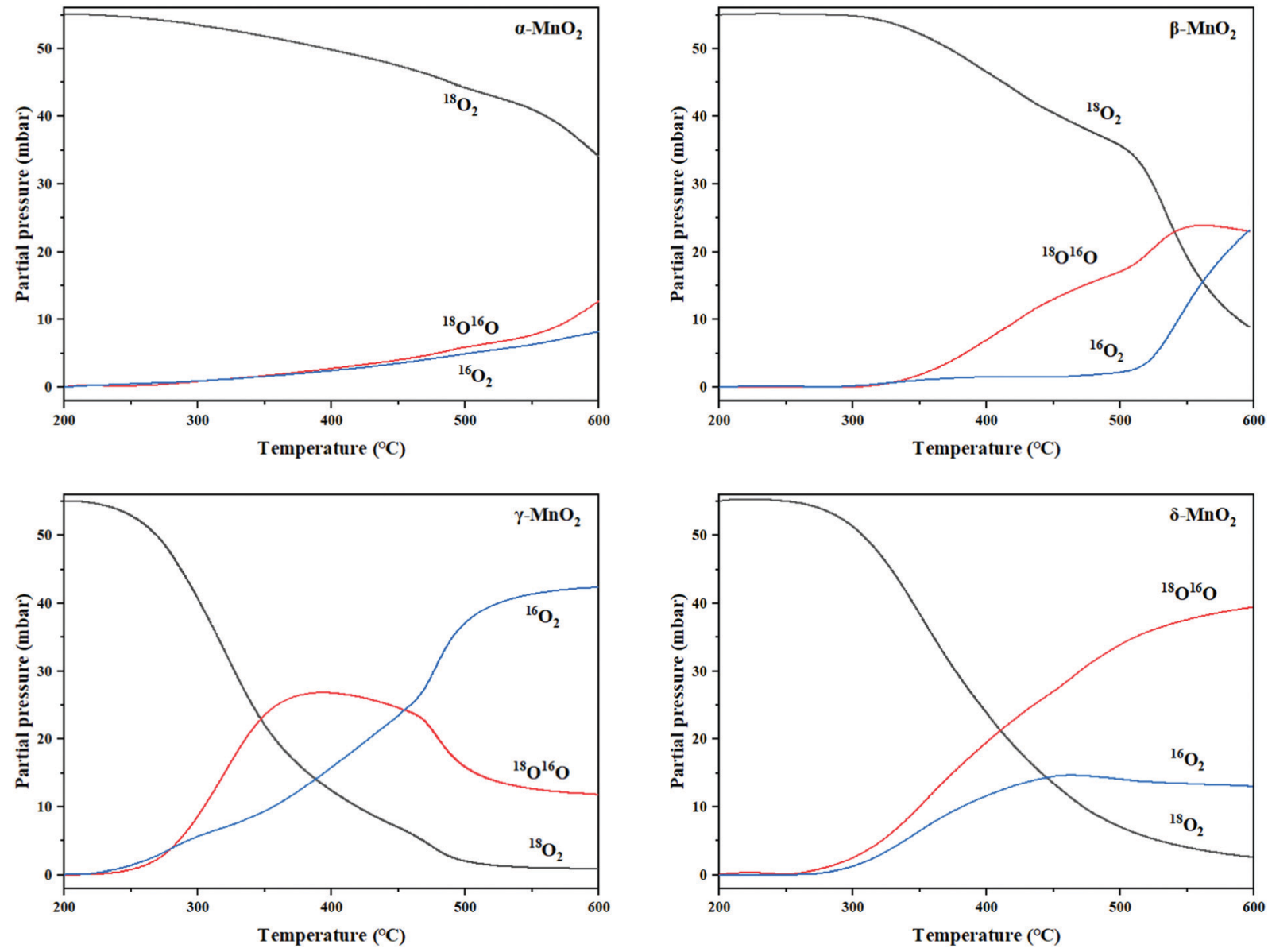

Fig. 6 Temperature programmed reaction of the ${ }^{18} \mathrm{O}_{2} /{ }^{16} \mathrm{O}_{2}$ isotopic exchange of $\mathrm{MnO}_{2}$.
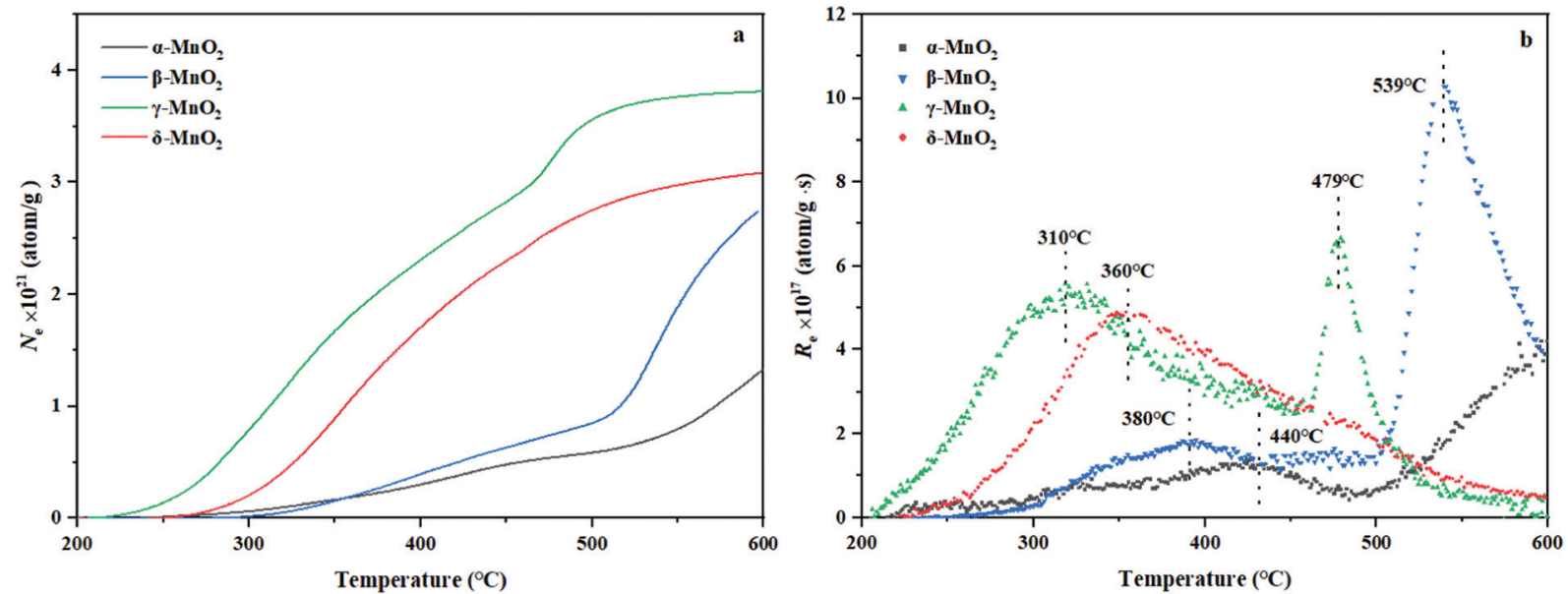

Fig. 7 (a) The curves of the total amount of exchanged ${ }^{18} \mathrm{O}\left(N_{\mathrm{e}}\right)$ and (b) the exchange rate $\left(R_{\mathrm{e}}\right)$ with temperature of $\mathrm{MnO}_{2}$.

starts at $200{ }^{\circ} \mathrm{C}$ for $\gamma-\mathrm{MnO}_{2}, 220{ }^{\circ} \mathrm{C}$ for $\delta-\mathrm{MnO}_{2}, 240{ }^{\circ} \mathrm{C}$ for $\alpha-\mathrm{MnO}_{2}$, and $280{ }^{\circ} \mathrm{C}$ for $\beta-\mathrm{MnO}_{2}$ in an increasing order.

According to the $R_{\mathrm{e}}$ curves, activated temperature for the four $\mathrm{MnO}_{2}$ catalysts (Fig. 7b) indicated the discrepancy in oxygen mobility ability over these catalysts further. In the experimental temperature window, the maximum exchange rate $\left(R_{\text {emax }}\right)$ value emerges when the gas-solid phase balance of ${ }^{18} \mathrm{O}$ amounts is achieved, and thus the behavior of each catalyst could be distinguished by the starting exchange temperature at which the value of $R_{\mathrm{emax}}$ is constant, that is, 
the lower the starting temperature is, the faster the migration of oxygen is. As displayed in Fig. 7b, the mobility behavior of reactive oxygen species is ranked as follows: $\gamma-\mathrm{MnO}_{2}\left(310{ }^{\circ} \mathrm{C}\right)$ $>\delta-\mathrm{MnO}_{2}\left(360{ }^{\circ} \mathrm{C}\right)>\beta-\mathrm{MnO}_{2}\left(380{ }^{\circ} \mathrm{C}\right)>\alpha-\mathrm{MnO}_{2}\left(440{ }^{\circ} \mathrm{C}\right)$. It is verified that $\gamma-\mathrm{MnO}_{2}$ shows the most excellent activity toward the mobility of oxygen species which could be related to its abundant oxygen vacancies to yield the corresponding reactive oxygens. Actually, the formation of reactive oxygen species demands unequal activation energies in the process of isotopic ${ }^{18} \mathrm{O}$ exchange. Interestingly, $\gamma-\mathrm{MnO}_{2}$ and $\beta-\mathrm{MnO}_{2}$ have the second extreme points, which likely presented exchange with some lattice oxygens in bulk. In other words, the exchange of lattice oxygen becomes the highest with an increase in temperature. In conclusion, the oxygen mobility of $\gamma-\mathrm{MnO}_{2}$ is superior at both low and high temperatures, consistent with the $\mathrm{O}_{2}$-TPD result.

\section{5 $\mathrm{NH}_{3}-\mathrm{TPD}$}

The surface acidity of the catalyst was thought to play a key role in the cleavage of the $\mathrm{C}-\mathrm{Cl}$ bonding of CVOCs in our previous work. ${ }^{12}$ Herein, the surface acidity of the catalyst was analyzed by $\mathrm{NH}_{3}$-TPD and the acid amounts of these as-prepared $\mathrm{MnO}_{2}$ catalysts were estimated according to the integral area of the desorption curve. The curve can be divided into three peaks for temperatures $<200{ }^{\circ} \mathrm{C}, 200-400{ }^{\circ} \mathrm{C}$, and $>400{ }^{\circ} \mathrm{C}$, corresponding to the weakly, moderately and strongly acidic sites for adsorbed ammonia, respectively. ${ }^{27}$

For $\alpha-\mathrm{MnO}_{2}$, there are two peaks centered at 401 and $467{ }^{\circ} \mathrm{C}$, both of which belong to desorption at strong acid sites. There is only one peak centered at $510{ }^{\circ} \mathrm{C}$ in the $\mathrm{NH}_{3}$-TPD profile of $\beta-\mathrm{MnO}_{2}$, corresponding to the strong acid sites. $\gamma-\mathrm{MnO}_{2}$ shows four $\mathrm{NH}_{3}$ desorption peaks at 122, 176, 401 and $550{ }^{\circ} \mathrm{C}$; the former two peaks are assigned to desorption occurring at weak acid sites and the latter two are attributed to those occurring at strong acid sites. The $\mathrm{NH}_{3}$-TPD curve of $\delta-\mathrm{MnO}_{2}$ contains two desorption peaks centered at 402 and $463{ }^{\circ} \mathrm{C}$, both of which are due to desorption at strong acid sites. As displayed in Table 4, among the four samples, the existence of weak acid sites was found only in $\gamma-\mathrm{MnO}_{2}$, which contained the highest amount of total acid, whereas the lowest acid amount was observed in the case of $\beta-\mathrm{MnO}_{2}$. CVOCs were reported to be absorbed on acid sites or oxygen vacancies for dechlorination. $^{27}$ Thus, $\gamma-\mathrm{MnO}_{2}$ containing relatively abundant acid sites is likely beneficial for $\mathrm{C}-\mathrm{Cl}$ cleavage and $\mathrm{HCl}$ formation to achieve CVOC degradation by selective catalytic combustion.

\subsection{Catalyst performance}

The 1,2-DCE conversion with reaction temperature over the four kinds of $\mathrm{MnO}_{2}$ catalysts is depicted in Fig. 9a. In detail,

Table 4 The results of $\mathrm{NH}_{3}-\mathrm{TPD}$

\begin{tabular}{llll}
\hline Sample & $\begin{array}{l}\text { Weak acid } \\
\left.(\mu \mathrm{mol} \mathrm{g})^{-1}\right)\end{array}$ & $\begin{array}{l}\text { Moderate acid } \\
\left.(\mu \mathrm{mol} \mathrm{g})^{-1}\right)\end{array}$ & $\begin{array}{l}\text { Strong acid } \\
\left.(\mu \mathrm{mol} \mathrm{g})^{-1}\right)\end{array}$ \\
\hline$\alpha-\mathrm{MnO}_{2}$ & - & - & 67.4 \\
$\beta-\mathrm{MnO}_{2}$ & - & - & 4.4 \\
$\gamma-\mathrm{MnO}_{2}$ & 7.8 & - & 65.0 \\
$\delta-\mathrm{MnO}_{2}$ & - & - & 31.1
\end{tabular}

these catalysts follow the $\mathrm{T}_{50}$ order of $\gamma-\mathrm{MnO}_{2}\left(236{ }^{\circ} \mathrm{C}\right)<$ $\alpha-\mathrm{MnO}_{2}\left(331{ }^{\circ} \mathrm{C}\right)<\beta-\mathrm{MnO}_{2}\left(352{ }^{\circ} \mathrm{C}\right)<\delta-\mathrm{MnO}_{2}\left(397{ }^{\circ} \mathrm{C}\right)$. Compared to $\beta-, \gamma-$, and $\delta-\mathrm{MnO}_{2}, \gamma-\mathrm{MnO}_{2}$ exhibits the most superior catalytic activity in the whole temperature window. The $\mathrm{CO}_{2}$ yield as the desired oxidation products during the 1,2DCE combustion is shown in Fig. 9b. This shows that $\gamma-\mathrm{MnO}_{2}$ exhibited the most outstanding $\mathrm{CO}_{2}$ selectivity in the combustion of 1,2-DCE. What is more, it can be observed that the $\mathrm{CO}_{2}$ yield of the catalysts in the whole temperature window follows the order of $\gamma-\mathrm{MnO}_{2}>\alpha-\mathrm{MnO}_{2}>\beta-\mathrm{MnO}_{2}>\delta-\mathrm{MnO}_{2}$, which indicates that $\beta$ - and $\delta-\mathrm{MnO}_{2}$ would generate a larger number of chlorinated byproducts than $\alpha$ - and $\gamma-\mathrm{MnO}_{2}$ during the 1,2-DCE combustion. Besides, the yield of $\mathrm{HCl}$ is also shown in Fig. 9c, which is another key product that should be considered. The order of $\mathrm{HCl}$ yield is as follows: $\gamma-\mathrm{MnO}_{2}>\alpha-\mathrm{MnO}_{2}>\beta-\mathrm{MnO}_{2}>\delta-\mathrm{MnO}_{2}$.

As displayed in Fig. S2 (ESI $\dagger$ ), the chlorinated organic byproducts, including $\mathrm{C}_{2} \mathrm{H}_{3} \mathrm{Cl}, \mathrm{C}_{2} \mathrm{H}_{2} \mathrm{Cl}_{2}, 1,1,2-\mathrm{C}_{2} \mathrm{H}_{3} \mathrm{Cl}_{3}$ and $\mathrm{CCl}_{4}$, are hardly observed on $\alpha$ - and $\gamma-\mathrm{MnO}_{2}$, but these chlorinated byproducts are readily formed over $\beta$ - and $\delta-\mathrm{MnO}_{2}$, especially on $\delta-\mathrm{MnO}_{2}$, resulting in the $\mathrm{HCl}$ yield presenting an inflection point at $400{ }^{\circ} \mathrm{C}$, which indicates the occurrence of not only hydrochlorination but also polychlorination during the overall combustion process. Commonly, it is noticeable that all these chlorine-containing byproducts initially increased and then decreased with increasing temperature, which might vanish if the temperature was high enough. The further fatal $\mathrm{HCl}$ oxidation into $\mathrm{Cl}_{2}$ would readily induce the formation of polychlorinated byproducts such as $1,1,2-\mathrm{C}_{2} \mathrm{H}_{3} \mathrm{Cl}_{3}$ and $\mathrm{CCl}_{4}$, which are enhanced with increasing temperature. ${ }^{42}$ With further increase of temperature, these chlorinated byproducts will be gradually transformed into final target products. Although $\alpha-\mathrm{MnO}_{2}$ is not found to generate the chlorinated byproducts, the small amount of surface reactive oxygen species resulted in $\mathrm{CO}_{2}$ yield lower than that achieved over $\gamma-\mathrm{MnO}_{2}$ (Fig. 5 and 7). Owing to the small amount of acidity, $\beta$ - and $\delta-\mathrm{MnO}_{2}$ cannot easily break the $\mathrm{C}-\mathrm{Cl}$ bond to produce $\mathrm{HCl}$ for dechlorination which also makes further transformation of the chlorinated byproducts difficult (Fig. 8).

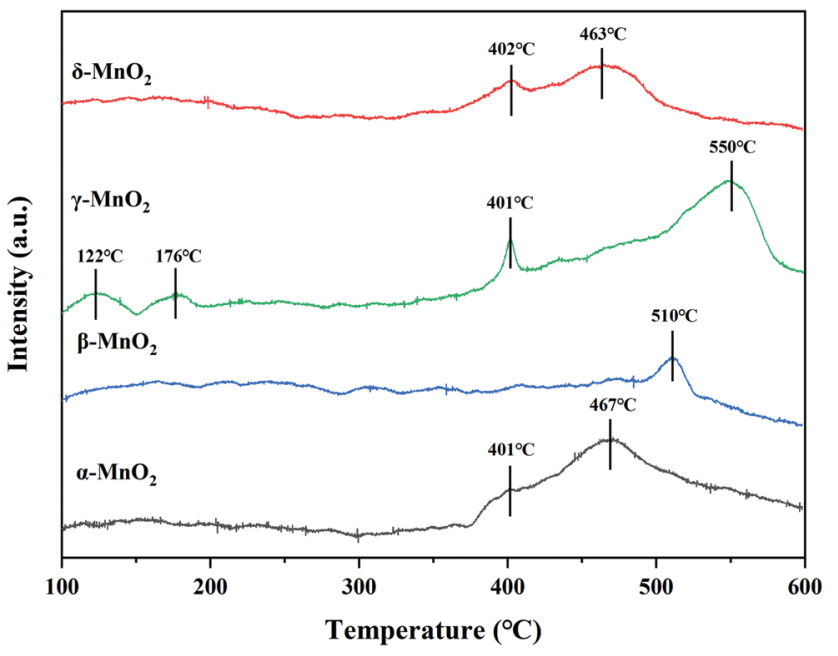

Fig. 8 The $\mathrm{NH}_{3}$-TPD profile of $\mathrm{MnO}_{2}$. 

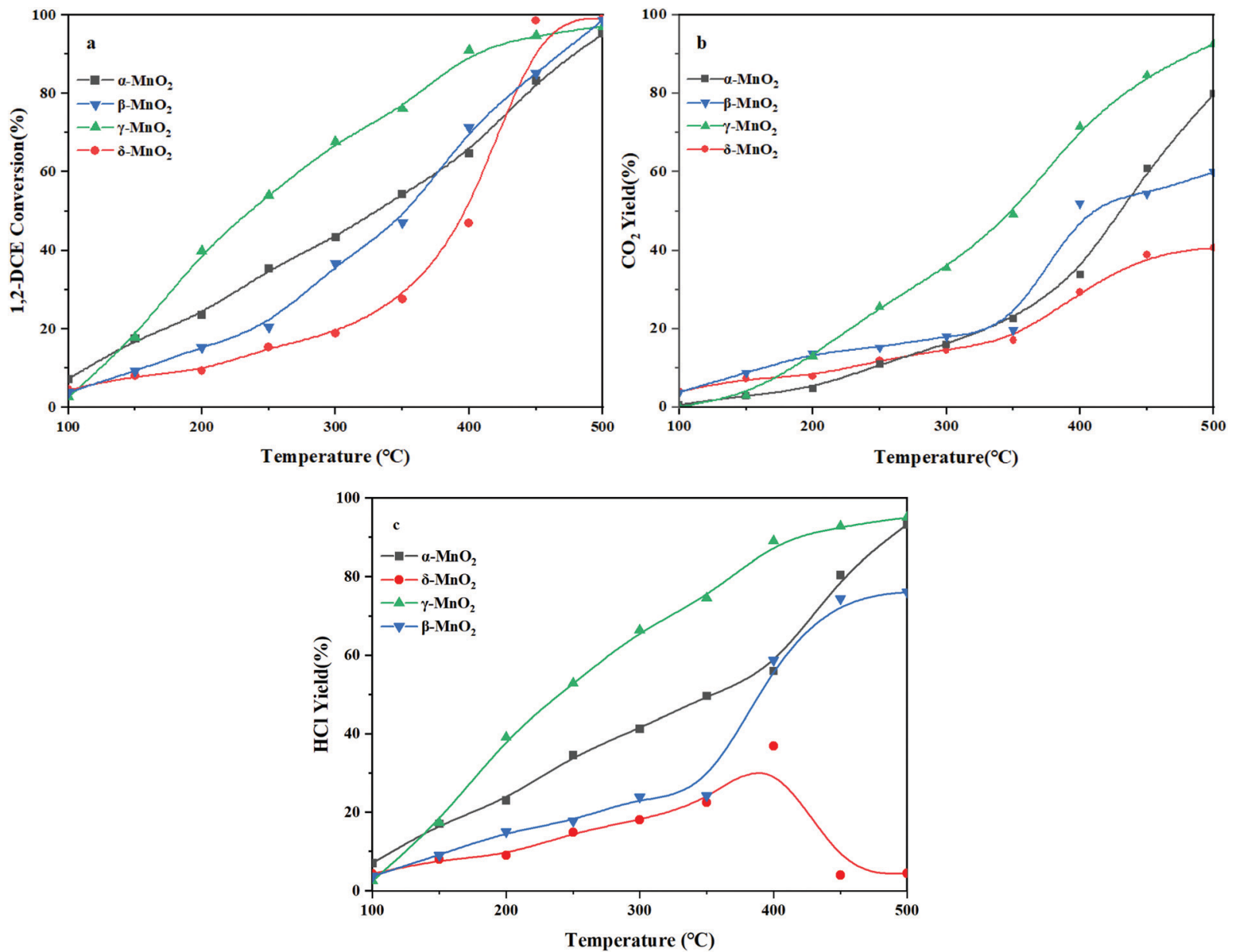

Fig. 9 (a) The conversion of 1,2-DCE, (b) $\mathrm{CO}_{2}$ yield and (c) $\mathrm{HCl}$ yield over $\mathrm{MnO}_{2}$ samples.

In spite of the reasonable redox properties of $\delta-\mathrm{MnO}_{2}$, it is unable to obtain a satisfactory $\mathrm{HCl}$ yield due to its enriched $\mathrm{Mn}^{4+}$, which results in strong $\mathrm{Mn}-\mathrm{Cl}$ bonding to induce the catalyst inactivation and promote the formation of a large number of polychlorinated compounds. As mentioned above, if the catalyst does not possess both acidic sites and redox properties, 1,2-DCE will not dissolve or break bonds thoroughly, which suppresses the $\mathrm{HCl}$ formation at low temperatures. That is to say, with further increase of temperature, the formation of $\mathrm{HCl}$ will be very hard unless the temperature is relatively high. From this, we can see that $\gamma-\mathrm{MnO}_{2}$ is the best catalyst for 1,2-DCE removal, which provides the highest yield of the final target product of $\mathrm{HCl}$ with a synergistic effect of acidity and redox properties. Its outstanding $\mathrm{CO}_{2}$ selectivity can be probably attributed to the superior reducibility and abundant surface reactive oxygens, as demonstrated by $\mathrm{H}_{2}$-TPR and OIE (Fig. 4 and 7), which achieves superior combustion of 1,2-DCE at relatively low temperatures. Moreover, the average oxidation state of the $\gamma-\mathrm{MnO}_{2}$ sample is the lowest among the four samples, which indicates that it possesses more surface oxygen vacancies and relatively few $\mathrm{Mn}^{4+}$ (Fig. 4 and 5). Combined with the $\mathrm{NH}_{3}$ TPD analysis mentioned above (Fig. 8), 1,2-DCE is firstly adsorbed and dissociated on the oxygen vacancies or the acid sites, preventing the formation of a rather stable $\mathrm{Mn}-\mathrm{Cl}$ bond and undesirable $\mathrm{Cl}_{2}$.

\subsection{In situ DRIFTS and reaction mechanism}

In situ DRIFTS of 1,2-DCE oxidation over the four kinds of $\mathrm{MnO}_{2}$ at different temperatures was conducted as shown in Fig. 10. Besides, the bands at 831 and $933 \mathrm{~cm}^{-1}$ over the $\beta-, \gamma-$ and $\delta-\mathrm{MnO}_{2}$ catalysts correspond to $\mathrm{C}-\mathrm{Cl}$ bond vibration. ${ }^{43,44}$ The $\mathrm{C}-\mathrm{Cl}$ bond vibration (Fig. 10b) appears on $\beta-\mathrm{MnO}_{2}$ when the temperature is higher than $200{ }^{\circ} \mathrm{C}$, which is related to the generation of $1,1,2-\mathrm{C}_{2} \mathrm{H}_{3} \mathrm{Cl}_{3}$ and $\mathrm{CCl}_{4}$ byproducts. The vibrational bands of this bonding for the $\gamma-\mathrm{MnO}_{2}$ sample are only visible at temperatures between 50 and $100{ }^{\circ} \mathrm{C}$ (Fig. 10c), which is supposed to be the remaining 1,2-DCE in the reaction. The $\mathrm{C}-\mathrm{Cl}$ bond vibration on $\delta-\mathrm{MnO}_{2}$ appears at $100-200{ }^{\circ} \mathrm{C}$, and the stretching vibration peak of $\mathrm{C}=\mathrm{C}$ on the ethylene substituent is also found at $1621 \mathrm{~cm}^{-1}$ (Fig. 10c), ${ }^{43}$ so it is inferred that $\mathrm{C}_{2} \mathrm{H}_{3} \mathrm{Cl}$ and cis $-\mathrm{C}_{2} \mathrm{H}_{2} \mathrm{Cl}_{2}$ are formed. Interestingly, the $\mathrm{C}-\mathrm{Cl}$ bond (Fig. 10a) was marginally observed on $\alpha-\mathrm{MnO}_{2}$, which is consistent with the activity data. The bands in the $1300-1500 \mathrm{~cm}^{-1}$ region over $\beta-, \gamma$ - and $\delta-\mathrm{MnO}_{2}$ are assigned to the deformed vibration peaks of $-\mathrm{CH}_{2}-$ and $-\mathrm{CH}$-groups, ${ }^{44}$ which are related to 1,2-DCE and the produced chlorinated 

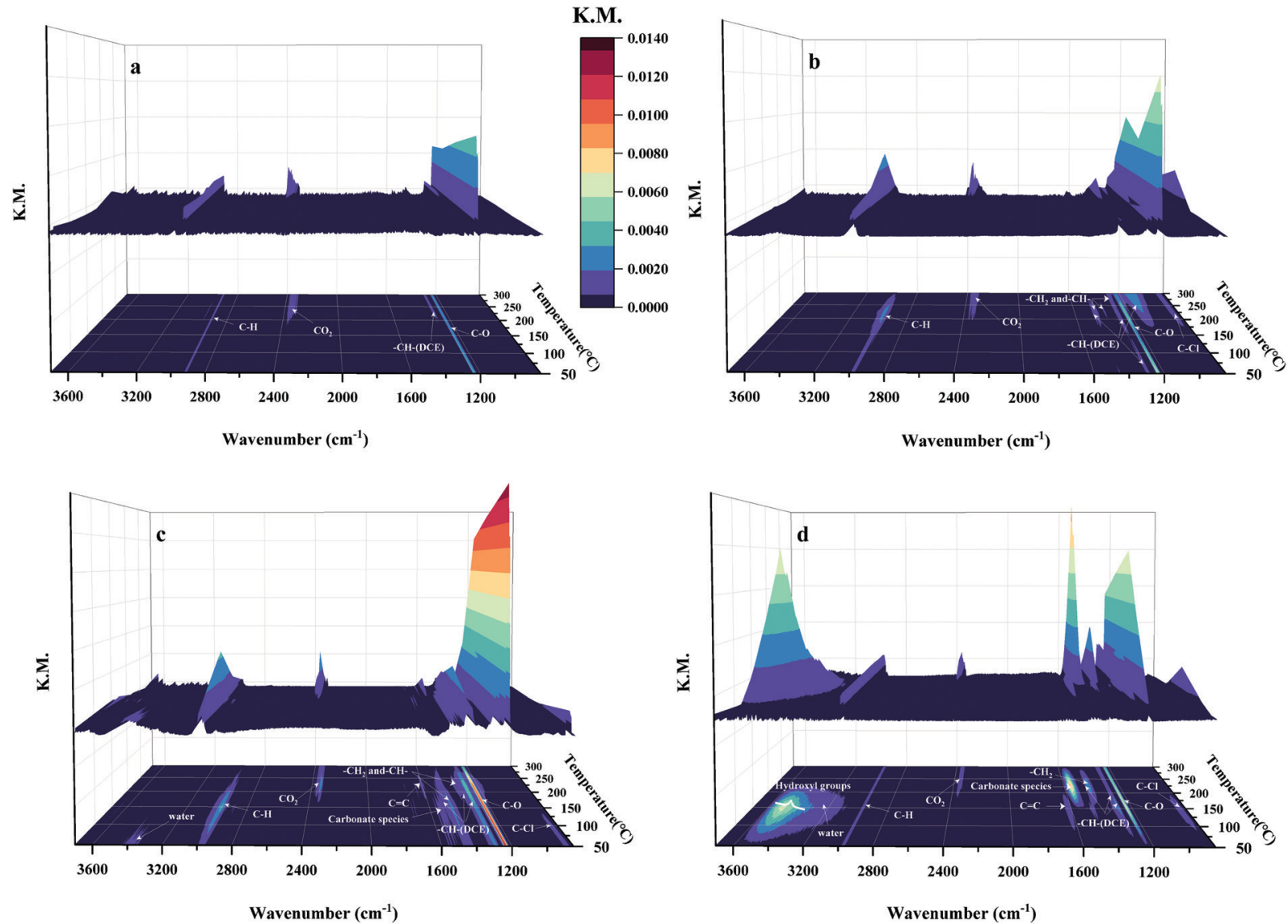

Fig. 10 The in situ DRIFTS results for oxidation of 1,2-DCE on (a) $\alpha-$, (b) $\beta-$, (c) $\gamma$ - and (d) $\delta-\mathrm{MnO}_{2}$ at different temperatures.

hydrocarbons. It is reported that the bands at 1226 and $1237 \mathrm{~cm}^{-1}$ are ascribed to the $\mathrm{C}-\mathrm{O}$ bond stretching vibration of acidic species, ${ }^{45}$ which indicates that the acetic acid species were produced by the oxidation of 1,2-DCE and then deeply oxidized to $\mathrm{H}_{2} \mathrm{O}$ and $\mathrm{CO}_{2}$. The bands at 1284, 1297 and $1464 \mathrm{~cm}^{-1}$ correspond to the vibration in the $-\mathrm{CH}$-group in 1,2 -DCE. ${ }^{46}$ The bands in the range of $3200-3600 \mathrm{~cm}^{-1}$ are associated with the $\mathrm{OH}$ group and water stretching vibration, which are observed over $\gamma$ - and $\delta-\mathrm{MnO}_{2} \cdot{ }^{47}$ As reported, the bands at 1555 and $1577 \mathrm{~cm}^{-1}$ over $\gamma$ - and $\delta-\mathrm{MnO}_{2}$ are assignable to the adsorbed carbonate species, ${ }^{12}$ which are the sources of generation of $\mathrm{CO}_{2}$ and $\mathrm{CO}$ products. Combining the results of previous characterization and Fig. 10, the probable combustion mechanisms of 1,2-DCE over the four kinds of $\mathrm{MnO}_{2}$ are summarized in Scheme 1. As reported, the chlorinated compounds caught by the oxygen vacancies are more unstable than those bonded with $\mathrm{Mn}^{4+}$ ions ${ }^{48}$ and tend to react to form $\mathrm{HCl}$, which facilitates $\mathrm{Cl}$ desorption. Hence, it is

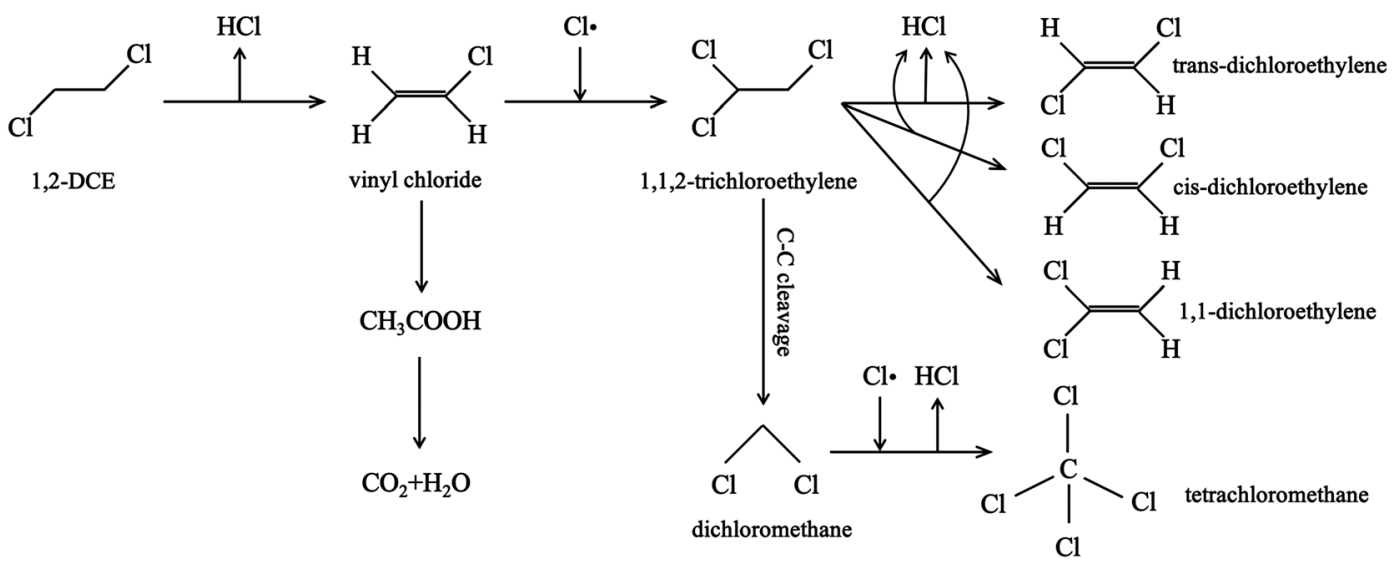

Scheme 1 The possible mechanisms of 1,2-DCE catalyst combustion over $\mathrm{MnO}_{2}$. 
deduced that 1,2-DCE is firstly activated at surface oxygen vacancies and successively destructed by acid sites via reaction with sufficient $\mathrm{H}$ atoms to generate $\mathrm{HCl}$ which is finally desorbed. $\mathrm{C}_{2} \mathrm{H}_{3} \mathrm{Cl}$ (by $\mathrm{HCl}$ elimination reaction), $\mathrm{C}_{2} \mathrm{H}_{2} \mathrm{Cl}_{2}$ (by $\mathrm{H}_{2}$ elimination reaction), $1,1,2-\mathrm{C}_{2} \mathrm{H}_{3} \mathrm{Cl}_{3}$ (by $\mathrm{HCl}$ addition or $\mathrm{Cl}$ substitution reaction) and $\mathrm{CCl}_{4}$ (Cl substitution reaction) byproducts are produced, which are thereafter oxidized to acetic acid species. $\mathrm{CO}_{2}$ and $\mathrm{CO}$ products are generated by the deep oxidation of acetic acid species and carbonate species. Based on the above analysis, we can find that $\gamma-\mathrm{MnO}_{2}$ with outstanding $\mathrm{C}-\mathrm{Cl} / \mathrm{C}-\mathrm{H}$ cleavage ability displays a better catalytic performance during the 1,2-DCE combustion process, which is attributed to the abundant oxygen vacancies, excellent surface oxygen migration ability, more acid sites and less $\mathrm{Mn}^{4+}$ content on the surface. Furthermore, there are relatively abundant acid sites and few $\mathrm{Mn}^{4+}$ in $\alpha-\mathrm{MnO}_{2}$, and thus we almost cannot

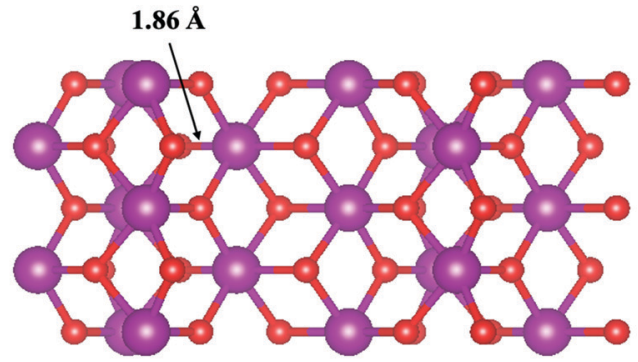

a1

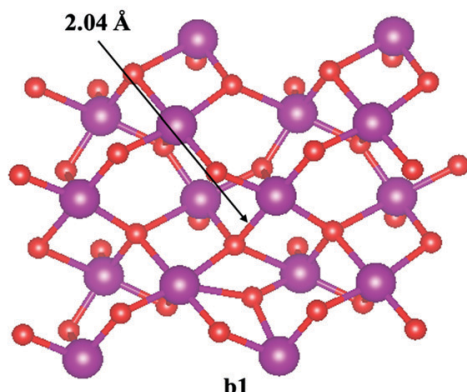

b1

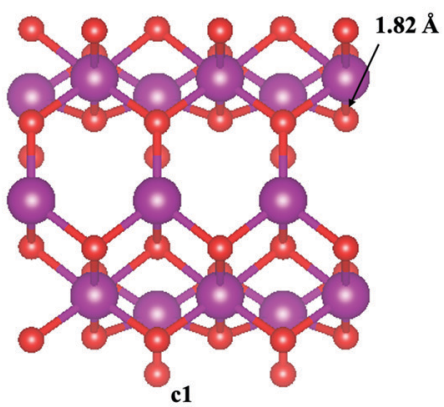

$1.95 \AA$

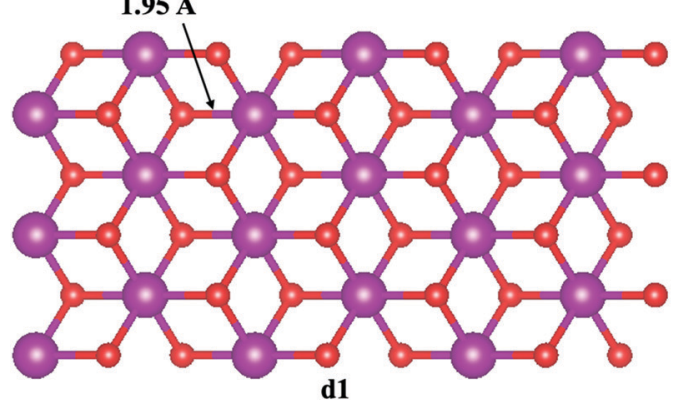

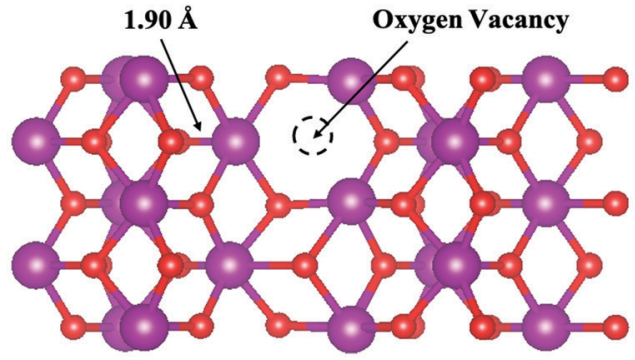

a2
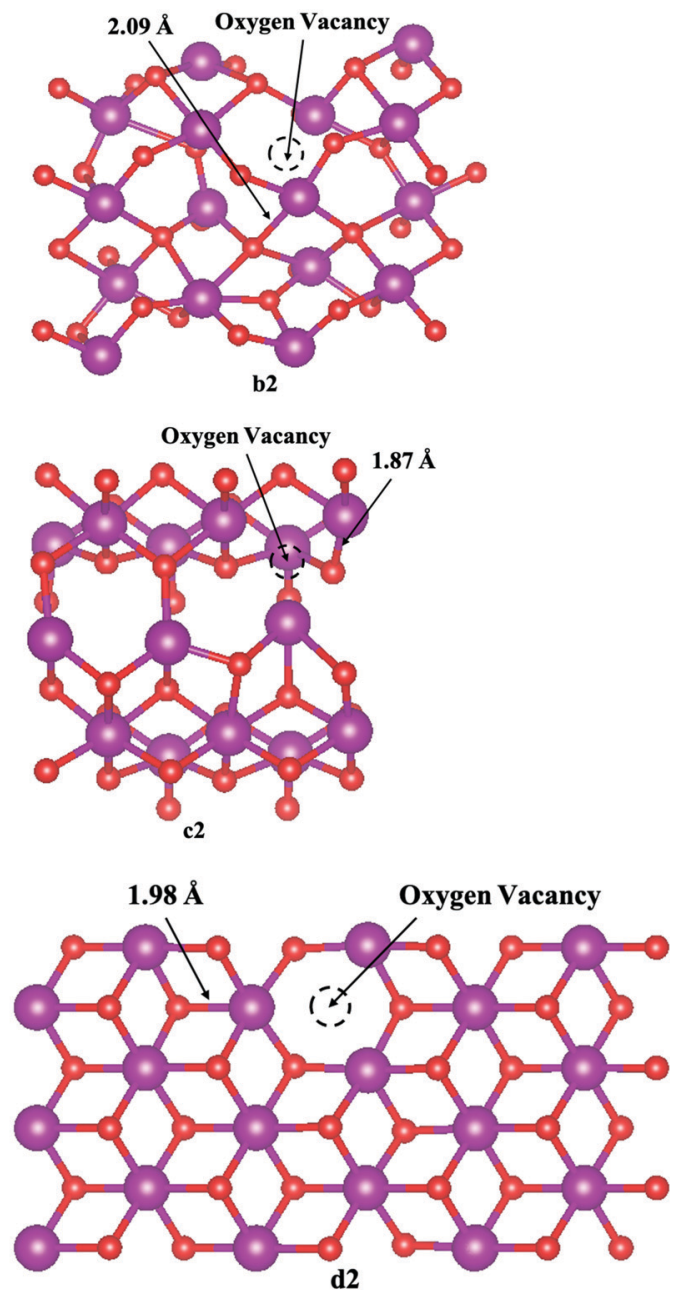

:Mn $\odot: 0$

Fig. 11 Model structures of (a) $\alpha-$, (b) $\beta-$, (c) $\gamma$ - and (d) $\delta-\mathrm{MnO}_{2}$ (a1-d1) without and (a2-d2) with oxygen vacancies. 
observe any chlorinated byproducts, but the yield of $\mathrm{CO}_{2}$ is essentially low because of the poor exchange capacity of the surface oxygen of $\alpha-\mathrm{MnO}_{2}$. The AOS of the Mn element on the surface of $\beta-\mathrm{MnO}_{2}$ and $\delta-\mathrm{MnO}_{2}$ is relatively high, and there are many $\mathrm{Mn}^{4+}$ species. 1,2-DCE mainly dissociates on $\mathrm{Mn}^{4+}$ to form a stable $\mathrm{Mn}-\mathrm{Cl}$ bond, leading to serious catalyst deactivation.

\subsection{DFT calculations}

As discussed in the preceding characterization, the surface reactive oxygen species of $\mathrm{MnO}_{2}$ play an important role in 1,2-DCE catalytic combustion reactions. It is believed that the formation of oxygen vacancies is due to an easy loss of the lattice oxygen, and thereafter a large number of surface reactive oxygens can be generated upon these ionic vacancies through a redox cycle, which is conducive to the fast migration of surface oxygen species. ${ }^{36}$ Therefore, the easy formation of oxygen vacancies theoretically supports the high amount of surface reactive oxygens. $\gamma-\mathrm{MnO}_{2}$ exhibited the highest specific surface area of $87.4 \mathrm{~m}^{2} \mathrm{~g}^{-1}$ associated with the best catalytic performance, while $\delta-\mathrm{MnO}_{2}$ exhibited the second largest specific surface area of $86.5 \mathrm{~m}^{2} \mathrm{~g}^{-1}$; however, it showed the worst catalytic performance. Thus, the specific surface area should not be the only factor affecting the catalytic performances of the four samples although a higher surface area usually leads to a better activity. In addition, the morphology, especially for the exposed facet, was considered and correlated to catalytic performances in the present work. The diverse morphologies observed by high-resolution transmission electron microscopy (Fig. 3) indicate the distinct crystal planes formed over the as-prepared samples. As illustrated in Fig. 11, a theoretical calculation on the exposed facets was conducted. Herein, the formation energy of oxygen vacancies by removing a lattice oxygen atom from the four kinds of $\mathrm{MnO}_{2}$ catalysts was calculated based on eqn (4):

$$
E_{\mathrm{Ov}}=E_{\text {sys-O }}-E_{\text {sys }}+E_{\mathrm{O} 2} / 2
$$

Here, $E_{\text {sys-o }}$ represents the energy of the system with oxygen vacancies, $E_{\mathrm{sys}}$ represents the energy of the system, and $E_{\mathrm{O}_{2}}$ represents the energy of the $\mathrm{O}_{2}$ molecules.

It is noticed that the lengths of the $\mathrm{Mn}-\mathrm{O}$ bonds around the oxygen vacancies were all extended because of the Jahn-Teller effect, ${ }^{49}$ causing more activated lattice oxygen to take part in the reaction readily. The $E_{\mathrm{Ov}}$ of $\alpha-, \beta-, \gamma$ - and $\delta-\mathrm{MnO}_{2}$ is $1.79 \mathrm{eV}$, $3.23 \mathrm{eV}, 1.47 \mathrm{eV}$ and $2.59 \mathrm{eV}$, respectively. It is clear that the energy for oxygen vacancy formation follows the sequence: $\beta-\mathrm{MnO}_{2}>\delta-\mathrm{MnO}_{2}>\alpha-\mathrm{MnO}_{2}>\gamma-\mathrm{MnO}_{2}$, which suggests that the oxygen vacancy is likely to be generated over the $\gamma-\mathrm{MnO}_{2}$ sample, resulting in adsorption of more reactive oxygen species, which makes it easier to be adsorbed as molecular oxygen and further dissociated on these surface vacancies, in accordance with the results of the present OIE experiment. To sum up the above discussion, we think that morphology is a more crucial factor than specific surface area that can significantly impact the redox ability and thereby improve the corresponding activity.

\section{Conclusions}

In summary, the preparation of $\alpha-, \beta-, \gamma$-, and $\delta$-type $\mathrm{MnO}_{2}$ was successful for 1,2-DCE catalyst combustion. $\gamma-\mathrm{MnO}_{2}$ displayed the most excellent catalytic activity to achieve an almost complete oxidation of 1,2-DCE with a synergistic effect of excellent redox properties and strong acidity during the 1,2-DCE oxidation process $\left(T_{90}=406{ }^{\circ} \mathrm{C}, y_{\mathrm{CO} 2}=92 \%\right.$ and $\left.y_{\mathrm{HCl}}=95 \%\right)$ at $42857 \mathrm{~mL} \mathrm{~g}^{-1} \mathrm{~h}^{-1}$ GHSV. It is confirmed that oxygen vacancies tend to form on the surface of $\gamma-\mathrm{MnO}_{2}$ based on DFT calculations. What is more, combined with $\mathrm{O}_{2}$-TPD, $\mathrm{NH}_{3}$-TPD and TPOIE technique analyses, $\gamma-\mathrm{MnO}_{2}$ was confirmed to exhibit the most superior surface oxygen migration owing to the enriched surface reactive oxygens on the ionic vacancies. Based on the $\mathrm{H}_{2}$-TPR and XPS analyses, having less $\mathrm{Mn}^{4+}$ on the surface significantly reduced the formation of strong $\mathrm{Mn}-\mathrm{Cl}$ bonding along with the adsorption of 1,2-DCE, which makes it easy to facilitate the subsequent reaction yielding polychlorinated byproducts. Moreover, the corresponding intermediates could be transformed into $\mathrm{CO}_{2}$ and $\mathrm{H}_{2} \mathrm{O}$ over catalysts with good redox properties. Besides, it is proved that the $\mathrm{HCl}$ formation and $\mathrm{C}-\mathrm{Cl}$ bond cleavage ability are related to both the relatively abundant acid sites and the surface mobile oxygens, which accelerates the formation of $\mathrm{HCl}$ and finally enables conversion into $\mathrm{CO}_{2}$ and $\mathrm{H}_{2} \mathrm{O}$. Both the dehydrochlorination by $\mathrm{HCl}$ elimination and the polychlorination by $\mathrm{Cl}$ substitution contribute to the formation of chlorinated byproducts including $\mathrm{C}_{2} \mathrm{H}_{3} \mathrm{Cl}, \mathrm{C}_{2} \mathrm{H}_{2} \mathrm{Cl}_{2}, 1,1,2-\mathrm{C}_{2} \mathrm{H}_{3} \mathrm{Cl}_{3}$ and $\mathrm{CCl}_{4}$.

\section{Author contributions}

Baicheng Shi: resources, writing - original draft, data curation, formal analysis, writing - review \& editing. Runduo Zhang: supervision, funding acquisition, validation. Zhaoying Di: investigation, validation. Xiaonan Guo: investigation, visualization. Ying Wei: project administration, visualization. Jingbo Jia: project administration, visualization.

\section{Conflicts of interest}

The authors declare that they have no competing financial interests.

\section{Acknowledgements}

The financial support from the National Natural Science Foundation of China (No. U1862102, 22176010 and 21976012) and the Fundamental Research Funds for the Chinese Central Universities (No. XK1802-1 and JD2117) is gratefully acknowledged.

\section{References}

1 C. He, Z. Jiang, M. Ma, X. Zhang, M. Douthwaite, J. Shi and Z. Hao, Understanding the promotional effect of $\mathrm{Mn}_{2} \mathrm{O}_{3}$ on micro-/mesoporous hybrid silica nanocubic-supported $\mathrm{Pt}$ catalysts for the low-temperature destruction of methyl ethyl 
ketone: an experimental and theoretical study, ACS Catal., 2018, 8, 4213-4229.

2 S. Wang and J. Hao, Air quality management in China: issues, challenges, and options, J. Environ. Sci., 2012, 24, 2-13.

3 M. Tian, M. Ma, B. Xu, C. Chen, C. He, Z. Hao and R. Albilali, Catalytic removal of 1,2-dichloroethane over LaSrMnCoO $_{6} / \mathrm{H}-\mathrm{ZSM}-5$ composite: insights into synergistic effect and pollutant-destruction mechanism, Catal. Sci. Technol., 2018, 8, 4503-4514.

4 A. Jamal, M. M. Rahman, S. B. Khan, M. Faisal, K. Akhtar, M. A. Rub, A. M. Asiri and A. O. Al-Youbi, Cobalt doped antimony oxide nano-particles based chemical sensor and photo-catalyst for environmental pollutants, Appl. Surf. Sci., 2012, 261, 52-58.

5 M. S. Kamal, S. A. Razzak and M. M. Hossain, Catalytic oxidation of volatile organic compounds (VOCs) - A review, Atmos. Environ., 2016, 140, 117-134.

6 T. Chang, Z. Shen, Y. Huang, J. Lu, D. Ren, J. Sun, J. Cao and H. Liu, Post-plasma-catalytic removal of toluene using $\mathrm{MnO}_{2}-\mathrm{Co}_{3} \mathrm{O}_{4}$ catalysts and their synergistic mechanism, Chem. Eng. J., 2018, 348, 15-25.

7 C. He, J. Cheng, X. Zhang, M. Douthwaite, S. Pattisson and Z. Hao, Recent advances in the catalytic oxidation of volatile organic compounds: a review based on pollutant sorts and sources, Chem. Rev., 2019, 119, 4471-4568.

8 Q. Dai, L. Yin, S. Bai, W. Wang, X. Wang, X. Gong and G. Lu, Catalytic total oxidation of 1,2-dichloroethane over $\mathrm{VO}_{x} /$ $\mathrm{CeO}_{2}$ catalysts: further insights via isotopic tracer techniques, Appl. Catal., B, 2016, 182, 598-610.

9 W. Yang, Z. a. Su, Z. Xu, W. Yang, Y. Peng and J. Li, Comparative study of $\alpha-, \beta-, \gamma-$ and $\delta-\mathrm{MnO}_{2}$ on toluene oxidation: oxygen vacancies and reaction intermediates, Appl. Catal., B, 2020, 260, 18150.

10 X. Liu, L. Chen, T. Zhu and R. Ning, Catalytic oxidation of chlorobenzene over noble metals (Pd, Pt, Ru, Rh) and the distributions of polychlorinated by-products, J. Hazard. Mater., 2019, 363, 90-98.

11 P. Yang, Z. Shi, F. Tao, S. Yang and R. Zhou, Synergistic performance between oxidizability and acidity/texture properties for 1,2-dichloroethane oxidation over $(\mathrm{Ce}, \mathrm{Cr})_{x} \mathrm{O}_{2} /$ zeolite catalysts, Chem. Eng. Sci., 2015, 134, 340-347.

12 H. Wang, B. Peng, R. Zhang, H. Chen and Y. Wei, Synergies of Mn oxidative ability and ZSM-5 acidity for 1,2-dichloroethane catalytic elimination, Appl. Catal., B, 2020, 276, 118922.

13 B. de Rivas, R. López-Fonseca, C. Jiménez-González and J. I. Gutiérrez-Ortiz, Synthesis, characterisation and catalytic performance of nanocrystalline $\mathrm{Co}_{3} \mathrm{O}_{4}$ for gas-phase chlorinated VOC abatement, J. Catal., 2011, 281, 88-97.

14 Z. El Assal, S. Ojala, S. Pitkäaho, L. Pirault-Roy, B. Darif, J.-D. Comparot, M. Bensitel, R. L. Keiski and R. Brahmi, Comparative study on the support properties in the total oxidation of dichloromethane over Pt catalysts, Chem. Eng. J., 2017, 313, 1010-1022.

15 A. Aranzabal, M. Romero-Sáez, U. Elizundia, J. R. GonzálezVelasco and J. A. González-Marcos, Deactivation of H-zeolites during catalytic oxidation of trichloroethylene, J. Catal., 2012, 296, 165-174.

16 J. González-Prior, R. López-Fonseca, J. I. Gutiérrez-Ortiz and B. de Rivas, Oxidation of 1,2-dichloroethane over nanocube-shaped $\mathrm{Co}_{3} \mathrm{O}_{4}$ catalysts, Appl. Catal., B, 2016, 199, 384-393.

17 P. Yang, Z. Shi, S. Yang and R. Zhou, High catalytic performances of $\mathrm{CeO}_{2}-\mathrm{CrO}_{x}$ catalysts for chlorinated VOCs elimination, Chem. Eng. Sci., 2015, 126, 361-369.

18 X. Feng, M. Tian, C. He, L. Li, J. Shi, Y. Yu and J. Cheng, Yolk-shell-like mesoporous $\mathrm{CoCrO}_{x}$ with superior activity and chlorine resistance in dichloromethane destruction, Appl. Catal., B, 2020, 264, 118493.

19 H. Oliveira, Chromium as an environmental pollutant: insights on induced plant toxicity, J. Bot., 2012, 2012, 1-8.

20 G. Zhu, J. Zhu, W. Jiang, Z. Zhang, J. Wang, Y. Zhu and Q. Zhang, Surface oxygen vacancy induced $\alpha-\mathrm{MnO}_{2}$ nanofiber for highly efficient ozone elimination, Appl. Catal., B, 2017, 209, 729-737.

21 Z. Fan, Z. Wang, J. Shi, C. Gao, G. Gao, B. Wang, Y. Wang, X. Chen, C. He and C. Niu, Charge-redistribution-induced new active sites on (001) facets of $\alpha-\mathrm{Mn}_{2} \mathrm{O}_{3}$ for significantly enhanced selective catalytic reduction of $\mathrm{NO}$ by $\mathrm{NH}_{3}$, J. Catal., 2019, 370, 30-37.

22 J. Wang, H. Zhao, J. Song, T. Zhu and W. Xu, Structureactivity relationship of manganese oxide catalysts for the catalytic oxidation of (chloro)-VOCs, Catalysts, 2019, 9, 726.

23 Q. Feng, H. Kanoh and K. Ooi, Manganese oxide porous crystals, J. Mater. Chem., 1999, 9, 319-333.

24 L. Li, J. Shi, M. Tian, C. Chen, B. Wang, M. Ma and C. He, In situ fabrication of robust three dimensional ordered macroporous $\gamma-\mathrm{MnO}_{2} / \mathrm{LaMnO}_{3.15}$ catalyst for chlorobenzene efficient destruction, Appl. Catal., B, 2021, 282, 119565.

25 C. Zhang, H. Cao, C. Wang, M. He, W. Zhan and Y. Guo, Catalytic mechanism and pathways of 1,2-dichloropropane oxidation over $\mathrm{LaMnO}_{3}$ perovskite: an experimental and DFT study, J. Hazard. Mater., 2021, 402, 123473.

26 W. L. Wang, Q. Meng, Y. Xue, X. Weng, P. Sun and Z. Wu, Lanthanide perovskite catalysts for oxidation of chloroaromatics: secondary pollution and modifications, J. Catal., 2018, 366, 213-222.

27 X. Weng, Q. Meng, J. Liu, W. Jiang, S. Pattisson and Z. Wu, Catalytic oxidation of chlorinated organics over lanthanide perovskites: effects of phosphoric acid etching and water vapor on chlorine desorption behavior, Environ. Sci. Technol., 2019, 53, 884-893.

28 S. Royer, D. Duprez and S. Kaliaguine, Oxygen mobility in $\mathrm{LaCoO}_{3}$ perovskites, Catal. Today, 2006, 112, 99-102.

29 D. Martin and D. Duprez, Mobility of surface species on oxides. 1. isotopic exchange of ${ }^{18} \mathrm{O}_{2}$ with ${ }^{16} \mathrm{O}$ of $\mathrm{SiO}_{2}, \mathrm{Al}_{2} \mathrm{O}_{3}$, $\mathrm{ZrO}_{2}, \mathrm{MgO}, \mathrm{CeO}_{2}$, and $\mathrm{CeO}_{2}-\mathrm{Al}_{2} \mathrm{O}_{3}$. activation by noble metals. correlation with oxide basicity, J. Phys. Chem., 1996, 100, 9429-9438.

30 A. Galdikas, D. Duprez and C. Descorme, A novel dynamic kinetic model of oxygen isotopic exchange on a supported metal catalyst, Appl. Surf. Sci., 2004, 236, 342-355. 
31 Y. Chabre and J. Pannetier, Structural and electrochemical properties of the proton $/ \gamma-\mathrm{MnO}_{2}$ system, Prog. Solid State Chem., 1995, 23, 1-130.

32 J. Zhang, Y. Li, L. Wang, C. Zhang and H. He, Catalytic oxidation of formaldehyde over manganese oxides with different crystal structures, Catal. Sci. Technol., 2015, 5, 2305-2313.

33 S. Devaraj and N. Munichandraiah, Effect of crystallographic structure of $\mathrm{MnO}_{2}$ on its electrochemical capacitance properties, J. Phys. Chem. C, 2008, 112, 4406-4417.

34 V. P. Santos, M. F. R. Pereira, J. J. M. Órfão and J. L. Figueiredo, The role of lattice oxygen on the activity of manganese oxides towards the oxidation of volatile organic compounds, Appl. Catal., B, 2010, 99, 353-363.

35 W. Bao, H. Chen, H. Wang, R. Zhang, Y. Wei and L. Zheng, Pt nanoparticles supported on N/Ce-doped activated carbon for the catalytic oxidation of formaldehyde at room temperature, ACS Appl. Nano Mater., 2020, 3, 2614-2624.

36 M. Li, R. Zhang, H. Wang, H. Chen and Y. Wei, Role of the exposure facets upon diverse morphologies of cobalt spinels on catalytic $\operatorname{deN}_{2} \mathrm{O}$ process, Catal. Today, 2021, 376, 177-187.

37 K. Xiang, Z. Xu, T. Qu, Z. Tian, Y. Zhang, Y. Wang, M. Xie, X. Guo, W. Ding and X. Guo, Two dimensional oxygenvacancy-rich $\mathrm{Co}_{3} \mathrm{O}_{4}$ nanosheets with excellent supercapacitor performances, Chem. Commun., 2017, 53, 12410-12413.

38 G. Bai, H. Dai, J. Deng, Y. Liu, F. Wang, Z. Zhao, W. Qiu and C. T. $\mathrm{Au}$, Porous $\mathrm{Co}_{3} \mathrm{O}_{4}$ nanowires and nanorods: highly active catalysts for the combustion of toluene, Appl. Catal., A, 2013, 450, 42-49.

39 M. Toupin, T. Brousse and D. Bélanger, Charge storage mechanism of $\mathrm{MnO}_{2}$ electrode used in aqueous electrochemical capacitor, Chem. Mater., 2004, 16, 3184-3190.

$40 \mathrm{Y}$. Zhang, Electronegativities of elements in valence states and their applications. 1. electronegativities of elements in valence states, Inorg. Chem., 1982, 21, 3886-3889.
41 V. R. Galakhov, M. Demeter, S. Bartkowski, M. Neumann, N. A. Ovechkina, E. Z. Kurmaev, N. I. Lobachevskaya, Y. M. Mukovskii, J. Mitchell and D. L. Ederer, Mn 3s exchange splitting in mixed-valence manganites, Phys. Rev. B: Condens. Matter Mater. Phys., 2002, 65, 113102.

42 F. Lin, Z. Zhang, N. Li, B. Yan, C. He, Z. Hao and G. Chen, How to achieve complete elimination of Cl-VOCs: a critical review on byproducts formation and inhibition strategies during catalytic oxidation, Chem. Eng. J., 2021, 404, 126534.

43 W. Wang, Q. Zhu, Q. Dai and X. Wang, Fe doped $\mathrm{CeO}_{2}$ nanosheets for catalytic oxidation of 1,2-dichloroethane: effect of preparation method, Chem. Eng. J., 2017, 307, 1037-1046.

44 M. Tian, C. He, Y. Yu, H. Pan, L. Smith, Z. Jiang, N. Gao, Y. Jian, Z. Hao and Q. Zhu, Catalytic oxidation of 1,2dichloroethane over three-dimensional ordered mesomacroporous $\mathrm{Co}_{3} \mathrm{O}_{4} / \mathrm{La}_{0.7} \mathrm{Sr}_{0.3} \mathrm{Fe}_{0.5} \mathrm{Co}_{0.5} \mathrm{O}_{3}$ : destruction route and mechanism, Appl. Catal., A, 2018, 553, 1-14.

45 P. A. Tarantilis, A. Beljebbar, M. Manfait and M. Polissiou, FT-IR, FT-Raman spectroscopic study of carotenoids from saffron (Crocus sativus L.) and some derivatives, Spectrochim. Acta, Part A, 1998, 54, 651-657.

46 Y. Liu, W. Wu, Y. Guan, P. Ying and C. Li, FT-IR spectroscopic study of the oxidation of chlorobenzene over Mnbased catalyst, Langmuir, 2002, 18, 6229-6232.

47 J. Wu, Q. Xia, H. Wang and Z. Li, Catalytic performance of plasma catalysis system with nickel oxide catalysts on different supports for toluene removal: effect of water vapor, Appl. Catal., B, 2014, 156-157, 265-272.

48 H. A. Miran, M. Altarawneh, Z. Jiang, H. Oskierski, M. Almatarneh and B. Z. Dlugogorski, Decomposition of selected chlorinated volatile organic compounds by ceria $\left(\mathrm{CeO}_{2}\right)$, Catal. Sci. Technol., 2017, 7, 3902-3919.

49 L. Chen, Y. Liu, X. Fang and Y. Cheng, Simple strategy for the construction of oxygen vacancies on alpha- $\mathrm{MnO}_{2}$ catalyst to improve toluene catalytic oxidation, J. Hazard. Mater., 2021, 409, 125020. 